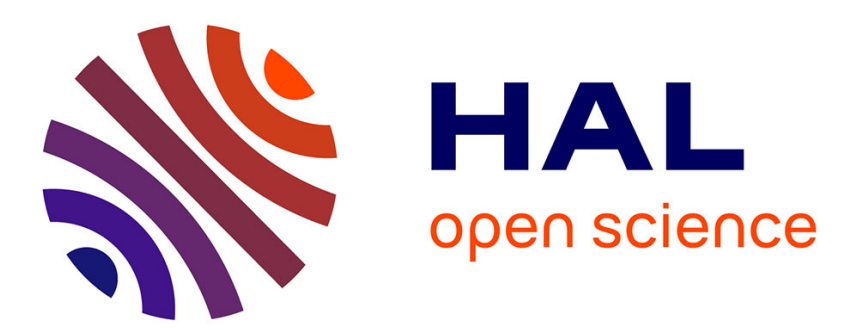

\title{
A review of a quarter century of International Workshops on Seismic Anisotropy in the crust (0IWSA-12IWSA)
}

\author{
Stuart Crampin, Yuan Gao
}

\section{- To cite this version:}

Stuart Crampin, Yuan Gao. A review of a quarter century of International Workshops on Seismic Anisotropy in the crust (0IWSA-12IWSA). Journal of Seismology, 2008, 13 (2), pp.181-208. 10.1007/s10950-008-9121-3 . hal-00478436

\section{HAL Id: hal-00478436 https://hal.science/hal-00478436}

Submitted on 30 Apr 2010

HAL is a multi-disciplinary open access archive for the deposit and dissemination of scientific research documents, whether they are published or not. The documents may come from teaching and research institutions in France or abroad, or from public or private research centers.
L'archive ouverte pluridisciplinaire HAL, est destinée au dépôt et à la diffusion de documents scientifiques de niveau recherche, publiés ou non, émanant des établissements d'enseignement et de recherche français ou étrangers, des laboratoires publics ou privés. 


\title{
A review of a quarter century of International Workshops on Seismic Anisotropy in the crust (0IWSA-12IWSA)
}

\author{
Stuart Crampin • Yuan Gao
}

Received: 9 June 2007 / Accepted: 10 January 2008 / Published online: 10 September 2008

(C) Springer Science + Business Media B.V. 2008

\begin{abstract}
In 25 years, the presence of azimuthally varying seismic anisotropy throughout the Earth's crust has progressed from general denial to universal acceptance, so that many international geophysical meetings now have sessions on seismic anisotropy. Over this period, the proceedings of the biennial series of International Workshops in Seismic Anisotropy (IWSAs) have captured many of the notable advances in the theory, calculation, observation and interpretation of particularly shear-wave splitting (seismic birefringence) in the Earth's crust. Shear-wave splitting is the almost-infallible indicator of seismic anisotropy
\end{abstract}

S. Crampin $(\varangle) \cdot$ Y. Gao

Shear-Wave Analysis Group, School of GeoSciences,

University of Edinburgh, Grant Institute,

West Mains Road, Edinburgh, EH9 3JW,

Scotland, UK

e-mail: scrampin@ed.ac.uk

URL: http://www.geos.ed.ac.uk/homes/scrampin/ opinion/

S. Crampin

Edinburgh Anisotropy Project,

British Geological Survey, Murchison House,

West Mains Road, Edinburgh, EH9 3LA,

Scotland, UK

Y. Gao

Institute of Earthquake Science,

China Earthquake Administration, 63 Fuxing Road,

100036, Beijing, China

e-mail: gaoyuan@seis.ac.cn along the ray path. This paper reviews 13 IWSA meetings (0IWSA-12IWSA) as a catalogue of 25 years of progress in seismic anisotropy. The evidence now suggests that shear-wave splitting monitors the low-level pre-fracturing deformation of the stress-aligned fluid-saturated microcracks pervading almost all in situ rocks in the crust. Shear-wave splitting indicates that microcracks are so closely spaced they are critical systems with all the universality, calculability, predictability, "butterfly wing's" sensitivity, and deterministic chaos that that implies. This leads to a New Geophysics, where low-level deformation can be monitored with shear-wave splitting, future behaviour calculated-predicted with the anisotropic poro-elastic model of rock evolution, and in some circumstances even potentially controlled by feedback. We anticipate the New Geophysics will greatly invigorate IWSA.

Keywords Anisotropy • International Workshop on Seismic Anisotropy (IWSA) · Shear-wave splitting • New Geophysics

\section{Introduction}

The first International Workshop on Seismic Anisotropy (1IWSA) was held in Suzdal, USSR, in 1982. The next, 2IWSA in 1986 in Moscow, 
was the first of 20 years of biennial meetings leading to 11IWSA 2004 in St Johns, Newfoundland and 12IWSA 2006 in Beijing. There was also a precursory meeting in 1975 in Paris that can justifiably be labelled 0IWSA. The proceedings of this quarter of a century of IWSA meetings have captured most of the significant markers spanning our understanding of seismic azimuthal anisotropy and shear-wave splitting in the upper half of the crust. Nowadays, stress-aligned seismic anisotropy is widely recognised in almost all rocks in the upper crust, so that international meetings, in both earthquake and particularly exploration seismology, frequently have sessions on seismic anisotropy. Here, we review the past quarter of a century of research into seismic azimuthal anisotropy and shear-wave splitting as marked by IWSA meetings. This review is timely, as it is now argued that the crack-critical crust, as revealed by shear-wave splitting, leads to a fundamental revision of solid earth geoscience.

The continuing IWSA workshops have been in various countries, organised by various people and sponsored by various organisations. Details are listed in Table 1, and the "Appendix" records how IWSA workshops began.

The first 11 IWSAs (including 0IWSA) had proceedings (11IWSA had abstracts, and proceedings of 12IWSA are currently in press, including this issue) published in a variety of international research journals (Table 1 ). These proceedings contain many papers crucial to the development of the theory, observation and interpretation of seismic anisotropy and outline the overall development of particularly azimuthal anisotropy in both earthquake and exploration seismology. Initially, IWSA meetings were almost entirely devoted to earthquake seismology. After 3IWSA, however, oil company sponsorship led to the almost complete dominance of exploration seismology. The reduction in earthquake studies is probably an overall loss to seismic anisotropy (and to IWSAs). We need to gain information about inaccessible subsurface rocks from as many sources as possible. The difference in pore fluids between hydrocarbons and water-based salt solutions probably makes little change to the structure or behaviour of fluid-saturated cracks, except during hydrocarbon production procedures.
Here, we review the series of IWSA meetings and identify papers, both at IWSA meetings and elsewhere, that have had a significant effect on the development of the understanding of seismic azimuthal anisotropy in the crust. Many of the important papers in anisotropy have appeared in IWSA proceedings. There are two principal exceptions: Thomsen (1986) defines the Thomsen parameters convenient for describing reflection surveys in the transverse isotropy of sedimentary sequences in seismic exploration and is the most highly cited paper in Geophysics; Crampin (1981) is an early review of wave propagation in cracked and anisotropic rock and is another highly cited paper.

\section{International workshops on seismic anisotropy}

2.1 0IWSA, 1975, Paris, France: proceedings in Geophys. J. R. Astron. Soc., 49, 1977

In 1975, the International Association of Seismology and Physics of the Earth's Interior Commission for Controlled Source Seismology held a meeting at the Institut de Physique du Globe, Université Paris, organised by David Bamford, on Seismic Anisotropy and its Implications. This meeting, 0IWSA (Table 1), was a direct precursor to 1IWSA. 0IWSA was the first meeting at which there had been a session, let alone a whole meeting (albeit only 1 day), devoted to seismic azimuthally varying anisotropy. At that time, azimuthal anisotropy in the Earth's crust had not been confirmed. In 1975, observations of seismic anisotropy in the Earth were confined to a comparatively thin layer at the top of the upper mantle, identified by two phenomena. Velocity variations of $P n$ waves propagating in oceanic basins displayed azimuthal velocity anisotropy, where the velocity perpendicular to the spreading centre are typically $5 \%$ greater than in directions parallel to the centre (Hess 1964; Raitt et al. 1969; and others). The second phenomenon was higher-mode surface-wave particle motions showing anisotropic coupling between higher-mode Love and Rayleigh waves which are controlled by the anisotropy in the uppermost few kilometres 
of the mantle (Crampin 1966; Crampin and King 1977). There were several earlier tentative reports of possible shear-wave splitting in the crust, but these were isolated unconfirmed examples-see the introduction to 0IWSA: Seismic anisotropythe state of the art (Bamford and Crampin 1977).

Theory Three papers by Keith and Crampin (1977a, b, c) calculated synthetic seismograms of (plane wave) body-wave propagation in multilayered azimuthally anisotropic media. Today, shear-wave splitting is the most diagnostic and widespread observation of azimuthal anisotropy in both the crust and upper mantle but, at that time (1975), anisotropy-induced shear-wave splitting was not a well-recognised phenomenon. The term shear-wave splitting for the differencing of shear-wave velocities in anisotropic media had been used (specifically $S$-wave splitting) by Crampin (1978) who calculated synthetic seismograms and polarisation diagrams (hodograms) of propagation through aligned cracks.

Observation and interpretation Bamford (1977) reported observations in the continental upper mantle of $P n$-wave azimuthal velocity anisotropy from explosion refraction studies. These had similar characteristics to earlier examples of $P n$-wave velocity anisotropy in oceanic basins from $P n$ refraction studies Hess (1964), which indicate a possibly thin layer of azimuthal anisotropy at the top of the upper mantle under oceanic basins.

Crampin and King (1977), using the techniques of Crampin and Taylor (1971), calculated the dispersion of surface waves in multi-layered anisotropic media, modelling previous observations of coupling between higher-mode Love and Rayleigh surface waves (Crampin 1966). Crampin and King showed that the coupling could be the result of as little as a $4-\mathrm{km}$ thickness of $4 \%$ shear-wave velocity anisotropy at the top of the upper mantle analogous to the $P n$-wave velocity anisotropy observed by Hess (1964) in oceanic basins and Bamford (1977) in the continental upper mantle. Fuchs (1977) discussed the possible causes of $P$-wave azimuthal anisotropy in the upper mantle in terms of dynamical processes.

Schlue and Knopoff (1977) inferred anisotropy in the upper mantle from the inability of isotropic inversion to yield consistent structures from both Love and Rayleigh surface-wave phase velocity dispersion across the Pacific Basin. This phenomenon, known as Rayleigh-Love polarisation anisotropy, was suggested by McEvilly (1964) and was later used extensively to imply upper-mantle anisotropy.

\subsection{IWSA, Suzdal, USSR, 1982: proceedings} in Geophys. J. R. Astron. Soc., 76, 1984

The first International Workshop on Seismic Anisotropy, 1IWSA, was held in Suzdal, USSR (Table 1). Again a state-of-the-art paper summarised the current position (Crampin et al. 1984a). Byerly (1938) had suggested that double refraction (shear-wave splitting) might be caused by varying shear-wave travel times, and Nur and Simmons (1969) demonstrated anisotropy in laboratory stress cells. Positive identification of seismic azimuthal anisotropy in the Earth were made by observations of shear-wave splitting in the crust and upper mantle by Crampin et al. (1980) and Ando et al. (1980, 1983), respectively.

Theory Crampin (1984a) surveyed wave propagation in cracked and anisotropic media in a brief summary of Crampin (1981)—a comprehensive review-which had been published elsewhere. A significant advance in calculating anisotropy was rotating elastic tensors so that the horizontal projection of wave propagation was in the $x$-direction, with $z$ vertical. This meant that analytical expressions and computer programs in multi-layered models could be written in concise general forms by making use of the summation convention for repeated suffices. This procedure is well adapted for computer manipulation and was one of the key features permitting the numerical developments in Crampin (1981) and many other theoretical and numerical calculations.

Červený and Firbas (1984) and Petrashen and Kashtan (1984) presented the theory for body-wave propagation in inhomogeneous anisotropic media but did not calculate synthetic seismograms. Martynov and Mikhailenko (1984) presented the theory for wave propagation in inhomogeneous anisotropic media and used a finite-difference technique to calculate synthetic 


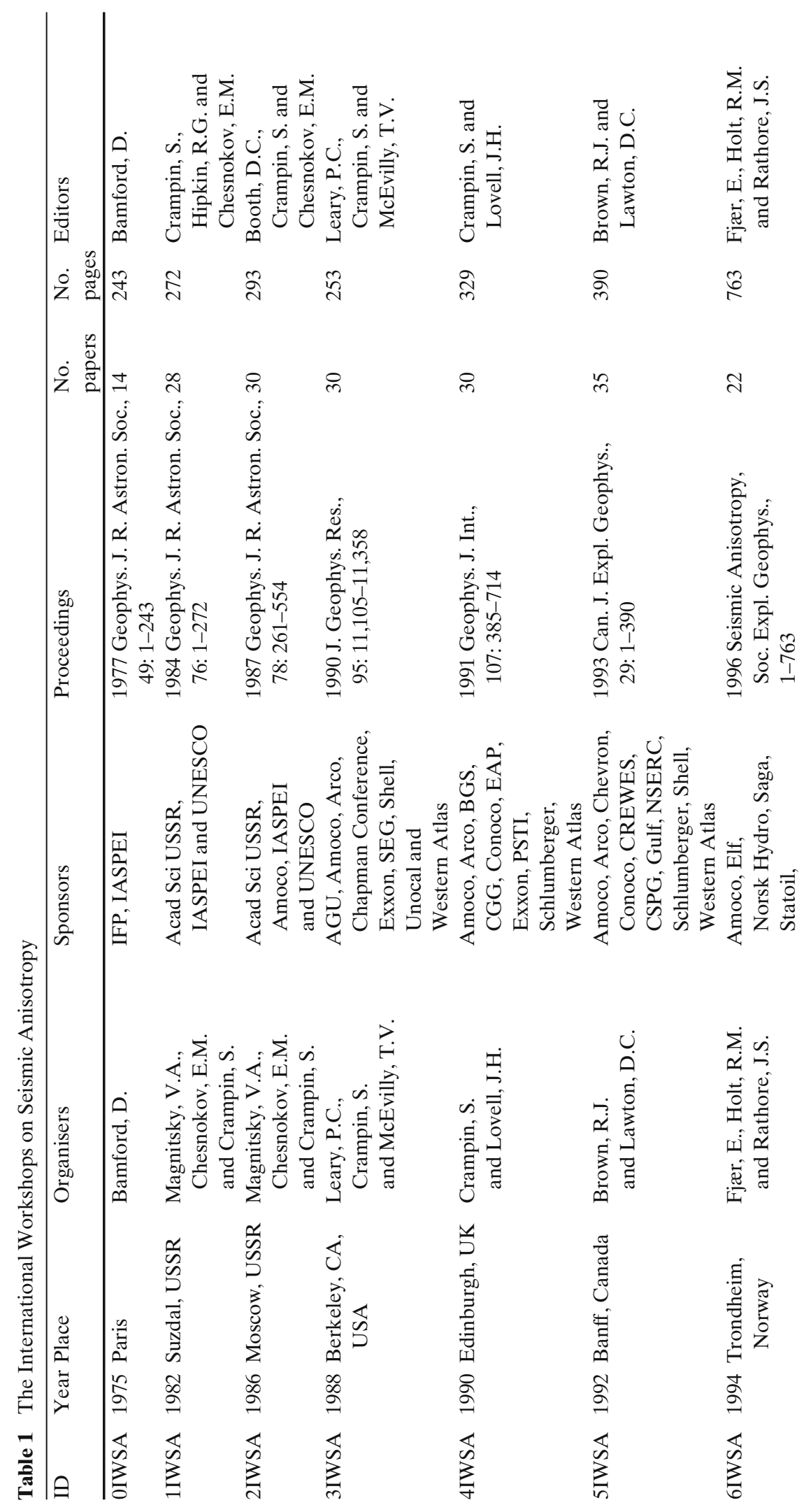




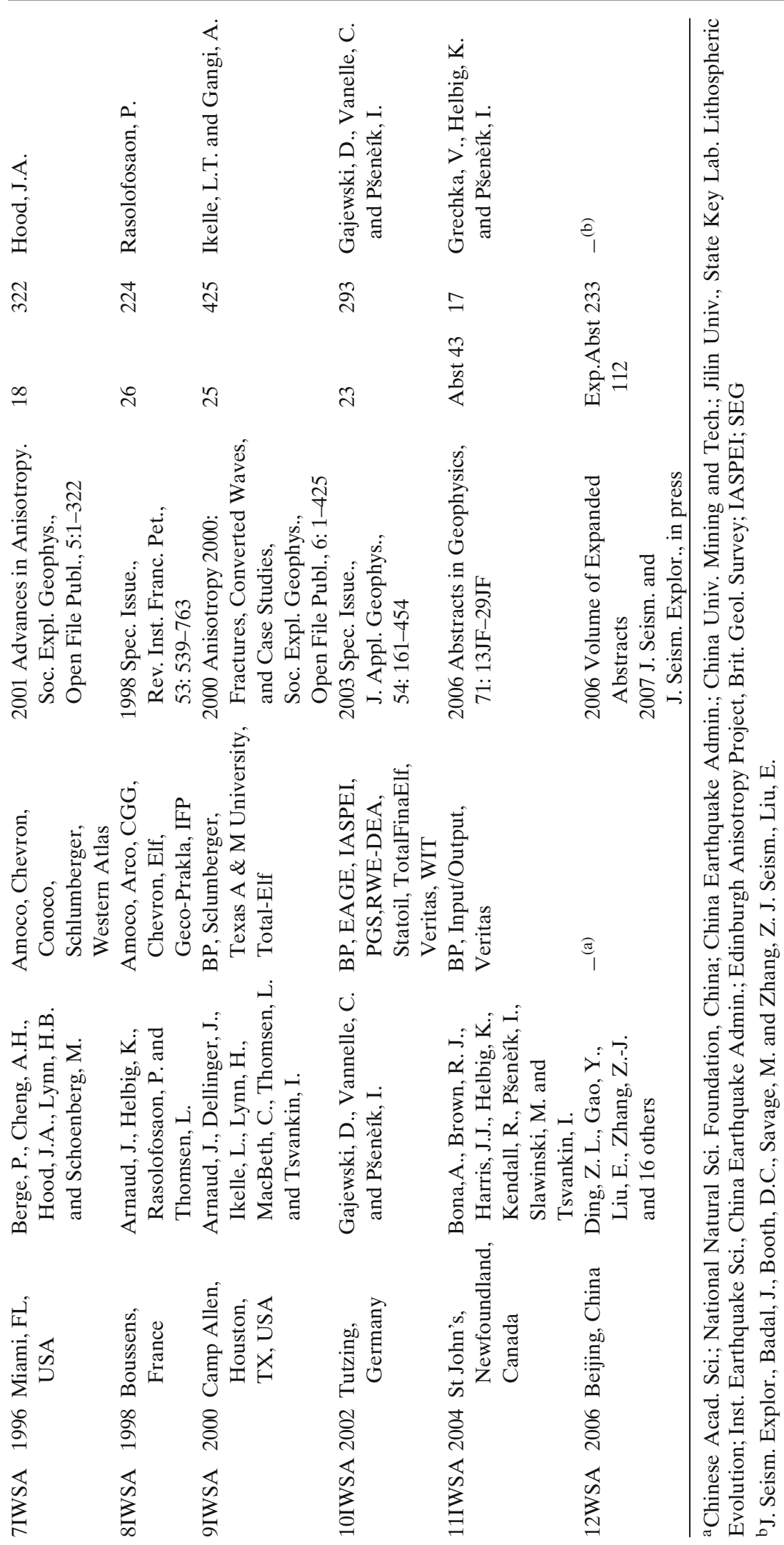


seismograms in a transversely isotropic half-space with a vertical axis of symmetry.

Evans (1984) recognised that the restriction of Nuttli (1961) to surface observations of teleseismic shear-wave arrivals also applied to higher-frequency shear-wave arrivals from crustal earthquakes. The restriction limits useful shearwave arrivals at a free surface to angles of incidence less than $\sin ^{-1} V s / V p \quad\left(\approx 35^{\circ}\right.$, for a Poisson's ratio of 0.25 ; Booth and Crampin 1985). This solid angle where true shear-wave arrivals are visible was later named the shear-wave window. Shear waves arriving outside the window are severely distorted by $S$-to- $P$ conversions at the free surface. Note that refraction through near-surface low-velocity layers frequently means that the effective shear-wave window above small earthquakes can often be extended to an effective straight-line shear-wave window of $45^{\circ}$ or $50^{\circ}$ (Booth and Crampin 1985). The area of the shear-wave window may also be severely distorted by the typical irregular surface topography above most earthquakes.

Crampin (1984b) used the equations of (Hudson 1980, 1981) to derive anisotropic elastic moduli for both liquid- and gas-filled (dry) stress-aligned cracks - a problem first suggested to Hudson (1981) by Crampin. The effectiveness of these developments for the calculation of seismic propagation through cracked structures has been confirmed in many publications and Hudson (1981) is now the standard much-cited reference. Valid for crack densities up to $\sim 0.05$, Hudson (1981) is often ineffectually challenged by attempts to extend the formulation to values beyond fracture criticality limit $(\sim 0.055)$ where no theory can correctly model elastic propagation in unstable material (Grechka 2006; Zheng et al. 2006). Crampin (1978) calculated synthetic seismograms through cracked media using anisotropic elastic moduli derived from the analyses of Garbin and Knopoff (1973, 1975a, b), which led to results compatible with those of Hudson (1981).

Using cracks to specify seismic anisotropy was an important advance for studies of anisotropy for at least two reasons. Distributions of stressaligned cracks are now the accepted source of the shear-wave splitting observed in exploration surveys by the oil industry (see "Sections 2.4",
4IWSA, and "Section 2.5", 5IWSA, below) and above small earthquakes (Crampin 1994). The anisotropy of cracks also meant that anisotropic elastic moduli could be easily modified in meaningful ways in terms of crack density, crack aspect ratio and crack orientation, so that shearwave splitting could be directly related to stress, porosity and other physical parameters. Since the elastic moduli of crystals are typically fixed and invariable, specifying cracks meant that shear-wave splitting became a flexible investigative tool.

Observation-field The proceedings contained 11 further papers on various observations of $P$ wave velocity anisotropy and shear-wave splitting in the crust and upper mantle and Rayleigh-Love polarisation anisotropy in the upper mantle.

Observation-laboratory Several authors discussed velocity anisotropy in laboratory tests of crystalline rocks. Christensen (1984) made comprehensive analyses of crystalline anisotropy in ultra-mafic upper-mantle rocks and suggested that shear-wave splitting would provide information about the mineral orientation and composition of the upper mantle, as indeed is now claimed. Babuška (1984) examined $P$-wave anisotropy of other crystalline rocks, and Babuška and Proz (1984) examined the closure of microcracks at increasing lithostatic pressures and concluded that $P$-wave anisotropy is only observed near the surface at low lithostatic pressures. Note however that these experiments were in drained specimens where fluids could escape. Cracks in undrained specimens do not close completely and shearwave splitting believed to be due to stress-aligned fluid-saturated cracks is now observed throughout the crust.

Interpretation-aligned cracks Crampin et al. (1984b) suggested that observations of shearwave splitting indicated that rocks in stressed fault zones are pervaded by fluid-saturated microcracks (named as extensive-dilatancy anisotropy or EDA). Stress-aligned shear-wave splitting is now seen in almost all rocks in the crust; see particularly Crampin (1993a, 1994). It is now generally, although not universally, accepted by both exploration and earthquake seismologists that the 
shear-wave splitting observed in almost all rocks is caused by stress-aligned fluid-saturated cracks and microcracks. Clearly, EDA cracks would be highly compliant and Crampin et al. (1984b) stimulated the search for temporal variations in shear-wave splitting before earthquakes. This later led to observations of temporal variations before earthquakes by Peacock et al. (1988), Crampin et al. (1990, 1991), Booth et al. (1990) and others and a successfully stress-forecast earthquake (Crampin et al. 1999), as well as variations in hydrocarbon reservoirs caused by fluid injection modelled by Angerer et al. (2002).

\subsection{IWSA, 1986, Moscow, USSR: proceedings in Geophys. J. R. Astron. Soc., 91, 1987}

The second International Workshop was in Moscow in 1986 (Table 1). As was anticipated in the state-of-the-art paper for 1IWSA (Crampin et al. 1984a), increasing interest in anisotropy meant that the whole field could no longer be reviewed in a few pages, and state-of-the-art papers were discontinued. As an example of the rapidly increasing interest, there was one report of shearwave splitting in the crust in 1980, three in 1985 and about 30 in 1986 (Booth et al. 1987).

Theory Several papers discussed various techniques for calculating full-wave synthetic seismograms in anisotropic structures including double-contour integration (Taylor 1987) and a ray algorithm for 3-D laterally inhomogeneous anisotropic layers (Gajewski and Pšenčík 1987), both of which were part of continuing developments.

Observation The Turkish Dilatancy Projects (TDP) were three deployments of radio-linked seismic networks spanning the North Anatolian Fault east of the Marmara Sea (TDP1 in 1979, TDP2 in 1980 and TDP3 in 1984). These experiments were designed to search for shearwave splitting above a persistent swarm of small earthquakes some $10 \mathrm{~km}$ SE of Izmit. (Coincidently, the TDP networks happened to span the epicenter, some 20 years later, of the devastating 1999, M7.5, Izmit earthquake. Unfortunately, the TDP sites have not been re-occupied). Shearwave splitting was indeed confirmed in the crust by Crampin et al. (1980), and five papers, following Crampin et al. (1985), reporting TDP1 and TDP2, set many of the parameters for observations of shear-wave splitting above small earthquakes. Evans et al. (1987) reporting TDP3 confirmed and enhanced previous results of TDP1 and TDP2.

TDP3 also deployed magneto-telluric (MT) stations (Evans et al. 1987). These MT sites showed regional contributions to the geoelectric-strike azimuths approximately parallel to the shearwave polarisations. Local contributions to the geoelectric-strike azimuths appeared to be exactly along the maxima of shear-wave polarisations, except at one station where there was severe topographic irregularity as it was on the edge of a $\sim 200$-m-deep gorge. (The effect of the shearwave window makes observations of shear-wave splitting extremely sensitive to near-station topography, and this was not recognised at the time of deployment). Anomalies in electromagnetic signals associated with earthquakes were directly correlated with stress-aligned microcracks.

Chen et al. (1987), aware of the in-house results of Peacock et al. (1988), also searched for temporal variations in the TDP records. In the 5-month deployment of TDP3, Chen et al. found an overall increase in time delays between split shear waves in time delays in Band- 1 directions within the shear-wave window normalised to millisecond per kilometre. Band- 1 is the doubleleafed solid angle $15^{\circ}$ to $45^{\circ}$ to the plane of the inferred parallel cracks (Crampin 1999). Increases in average time delays in this solid angle indicate increasing stress as in the accumulation of stress before earthquakes. The Band- 1 time delays showed an increase at five out of seven seismic stations, suggesting stress accumulation before an impending earthquake. This is likely to be associated with stress accumulation before an $M 4.8$ earthquake, some $45 \mathrm{~km} \mathrm{SW}$ of the centre of the network, on 28th October, 1984, 4 days after the monitoring had ended. At that time, possible associations had not been identified, as the great sensitivity of fluid-rock deformation to comparatively small stress changes at substantial distances had not yet been recognised. 
Observation Leary et al. (1987) and Li et al. (1987) presented observations and modelling of seismic propagation in the vicinity of the seismically active Oroville Fault in California and provided information about the aligned fractures surrounding the fault. Three papers reported various observations of anisotropic effects in USSR, including the very detailed multi-azimuth reflection surveys and vertical seismic profiles (VSPs) in transverse isotropy by Galperina and Galperin (1987).

Interpretation Crampin (1987) speculated on how changes in shear-wave splitting could forecast earthquakes (first suggested by Crampin 1978 and Crampin et al. 1984b). These ideas eventually led to observations of temporal changes (with hindsight) in Band-1 time delays before many earthquakes, including one successful stress forecast of an M5 earthquake in Iceland (Crampin et al. 1999). Note that Gupta (1973a) had earlier claimed to have observed temporal variations in shear-wave splitting before earthquakes. Unfortunately, Gupta (1973a) had misinterpreted laboratory experiments (Gupta 1973b) and identified crustal observations of shear-wave splitting so far outside the effective shear-wave window that they were completely uninterpretable in terms of our current understanding of shear-wave splitting (Crampin et al. 1981; Crampin 1994).

Note that Thomsen (1986) was an important paper, published elsewhere, defining appropriate parameters for exploration processing of weakly anisotropic transversely isotropic media with a vertical axis of symmetry (transverse isotropy (TIV) anisotropy). The Thomsen parameters are one of the major factors that opened up TIV anisotropy to exploration seismologists as is evident in 4IWSA and thereafter elsewhere.

\subsection{IWSA, 1988, Berkeley CA, USA: \\ proceedings in J. Geophys. Res., 95, 1990}

The Third International Workshop was in the Berkeley Campus of the University of California, USA (Table 1). The reports at this meeting were almost exclusively on laboratory and field observations of fracture and particularly microcrack anisotropy (Leary et al. 1990).
Theory Several papers calculated synthetic seismograms including: Gajewski and Pšenčík (1990) extending previous work in dynamic ray tracing (Gajewski and Pšenčík 1987) to calculate synthetic seismograms in multi-layered anisotropic substrates; Tsvankin and Chesnokov (1990) used double-contour integrals to calculate synthetic seismograms in orthorhombic media.

Liu and Crampin (1990) showed that, just as there is a shear-wave window limiting observations of shear waves at the free surface, there are also internal shear-wave windows limiting observations at each interface due to the different behaviour of $S V$ and $S H$ waves at horizontal interfaces. In some cases, the behaviour can suggest anisotropy-induced shear-wave splitting at isotropic-to-isotropic internal interfaces.

Observation Shih and Meyer (1990) used an automatic cross-correlation technique (Shih et al. 1989) to measure shear-wave splitting in Long Valley Caldera, CA, USA. They found anomalies associated with faults and larger time delays above the resurgent dome. Larger time delays are now recognised as being associated with rocks with high heat flow (Volti and Crampin 2003a, b). Savage et al. (1990) examined shear-wave splitting in Long Valley Caldera by visual techniques and obtained similar conclusions but attributed the scatter in time delays to near-receiver anisotropy. The large scatter above small earthquakes is now attributed to $90^{\circ}$ flips in shear-wave polarisations caused by the high pore-fluid pressures associated with all seismically active faults rearranging microcrack orientations (Crampin et al. 2004). $\left(90^{\circ}\right.$ flips are where the faster and slower split shear waves abruptly exchange polarisations, Angerer et al. 2002). Li et al. (1990) modelled observations of VSPs in the Mohave Desert, CA, USA, with synthetic seismograms and found shear-wave splitting consistent with interpretations in terms of sub-parallel sub-vertical cracks in other studies (for example, Evans et al. 1987). Li and Leary (1990) observed and modelled fault-zone-trapped waves in a thin anisotropic wave guide.

Kaneshima (1990) reviewed shear-wave splitting at some 40 seismic stations in Japan. Shear-wave splitting had been observed over a wide range of source zones and azimuths and 
Kaneshima concluded that shear-wave splitting may be limited to the uppermost $15-25 \mathrm{~km}$ of the crust.

Interpretation Shepherd (1990) gave a comprehensive geological analysis of microcracks, fluid inclusions and stress which generally supported the interpretation of shear-wave splitting in terms of propagation through sub-parallel sub-vertical fluid-saturated microcracks.

In an integrated study, Queen and Rizer (1990) found that the orientations of pressure-cracked core-sample discs matched the orientations of shear-wave splitting at the Conoco Borehole Test Facility in Oklahoma. This was a direct correlation of shear-wave splitting with microcrack lithology and suggested that the shear-wave splitting was directly related to overall fracture orientations and densities, where shear-wave polarisations indicate directions of preferred fluid flow. This has now been widely established in production reservoirs and elsewhere.

Crampin et al. (1990) showed that, when more data became available, the statistically significant increase of Band- 1 time delays identified by Peacock et al. (1988) at Station KNW of the Anza Seismic Network, Southern California, was immediately followed by the $M 6$ North Palm Springs of 8th July, 1986, $30 \mathrm{~km}$ distant from KNW. (The aftershocks of the earthquake had previously overloaded the location programme in California, which was why Peacock et al. could not recognise the association). This was the first time that temporal changes in Band-1 time delays monitoring the accumulation of stress before earthquakes had been observed (with hindsight) before earthquakes as suggested by Crampin (1978, 1987) and Crampin et al. (1984b). Similar increases were also seen (with hindsight) in Band-1 time delays before an M 3.8 swarm earthquake in Enola, AR, USA by Booth et al. (1990).

Note that the interpretation of Peacock et al. (1988) and Crampin et al. (1990) was challenged by Aster et al. (1990), who used an automatic measurement technique to infer that there were no temporal changes. Crampin et al. (1991; reply, Aster et al. 1991) showed that visual inspection of rotated seismograms indicated that the comments of Aster et al. (1990) could be discounted as some of their automatic measurements were in error by up to $200 \%$. Note that shear-wave splitting above small earthquakes is difficult to measure automatically on typical seismograms in the crust (Crampin and Gao 2006a). No wholly successful fully automatic technique has yet been established, except when there is rigorous selection of seismograms and rejection of, typically, well over $50 \%$ of the records. Except for vigorous aftershocks sequences, there are seldom enough earthquakes within the shear-wave window to make this useful, and aftershock sequences do not appear to have consistent patterns of stress variations. Note that an effective semi-automatic technique has now been developed (Gao et al. 2006).

\subsection{IWSA, 1990, Edinburgh, UK: proceedings in Geophys. J. Int., 107, 1991}

The Fourth International Workshop on Seismic Anisotropy, 4IWSA, was held in Edinburgh (Table 1). Previous IWSAs had principally discussed earthquake seismology. However, shear-wave splitting had now been observed in the oil reservoirs. The 1986 Annual International Society of Exploration Geophysicists (SEG) Meeting had 15 abstracts on exploration-based crack-induced shear-wave splitting-see for example, Alford (1986) and Lynn and Thomsen (1986). Recognising this advance, Crampin founded in 1988 the Edinburgh Anisotropy Project (EAP) at the British Geological Survey. Sponsored by $\sim 18$ oil companies, EAP still continues, directed by Xiang-Yang Li. As a result of this change of emphasis, 4IWSA in Edinburgh had well over $50 \%$ of the proceedings related to exploration seismology, and all succeeding IWSA have been increasingly dominated by exploration seismology as oil companies provided increasing sponsorship (Table 1).

The first paper, by Crampin and Lovell (1991), reviewed the first decade of observations of shearwave splitting in the Earth. Crampin and Lovell listed seven then unexplained features of shearwave splitting ranging from the coincidence of the degree of stress-aligned shear-wave velocity anisotropy in virtually all rock types to the huge $( \pm 80 \%)$ scatter in shear-wave time delays and polarisations above small earthquakes. It is a mark of 
the progress in understanding shear-wave splitting that these seven unexplained features in 1991 have all been largely resolved, principally as a result of the recognition that the fluid-saturated microcracks are so closely spaced that they are critical systems with all the new behaviour that this New Geophysics implies (Crampin 1998, 2003a, 2006; Crampin and Chastin 2001; Crampin and Peacock 2005; Crampin et al. 2003, 2004).

Theory Hudson (1991) reviewed the background and overall progress and conditions for modelling cracks in heterogeneous media begun 13 years earlier by Crampin (1978) and Hudson (1980, 1981).

$\mathrm{Li}$ and Crampin (1991a, b) developed the linear-transform technique, LTT, to analyse vector-polarised shear-wave data by writing the two horizontal components as complex numbers and successfully applied LTT to four very different case studies. This was the first time that a comprehensive analysis technique had been developed to analyse shear-wave splitting and was important as demonstrating that sophisticated fundamentally new techniques for analysing shear-wave splitting could be developed.

Lou and Crampin (1991) calculated synthetic seismograms and dispersion of interface waves propagating along thin anisotropic wave guides. Such guided waves in cross-hole seismics have been used to test continuity of wave guides in hydrocarbon reservoirs (Leary 2006).

\section{Theory and observation-shear-wave singularities} Wild and Crampin (1991) demonstrated the theoretical effects of solids with combinations of transverse isotropy (periodic thin layer (PTL) anisotropy) and azimuthal anisotropy (known as extensive-dilatancy anisotropy or EDA anisotropy) believed to be common in hydrocarbon reservoirs. PTL anisotropy is the transverse isotropy of periodic thin layers and the lithology of shales and mudstones with vertical axes of symmetry. EDA anisotropy is the azimuthal anisotropy of parallel vertical microcracks with horizontal axes of symmetry (Crampin et al. 1984b). One of the principal effects of a combination of PTL and EDA anisotropy is to yield orthorhombic anisotropic symmetry with numerous (theoretically up to 27) shear-wave point singularities (Crampin and Yedlin 1981).

Point singularities, where the faster and slower shear-wave sheets touch or intersect, can cause severe disturbances to shear-wave ray paths in directions passing within ten or more degrees of the singularity (depending on the relative strengths of PTL and EDA anisotropy). Crampin (1991) used ANISEIS (Taylor 1987, 1990) to calculate exact full-wave synthetic seismograms demonstrating the pronounced disturbances to shear-wave polarisations (including $90^{\circ}$ flips, Angerer et al. 2002) and time delays caused by point singularities, including abrupt reversal of signs (positive to negative, say) without passing through zero. Note that both radial and azimuthal integration were used and the full-wave seismograms are exact without approximations. Bush and Crampin (1991) confirmed the effects of point singularities in observations of a multi-offset VSP in the Paris Basin.

Observation The Proceedings of 4IWSA had some ten papers on observations of $P$-wave velocity anisotropy and shear-wave splitting in hydrocarbon reservoirs. There were also several examples of inverting both field and laboratory data for elastic parameters (Artemieva and Chesnokov 1991; Brodov et al. 1991; Brown et al. 1991; de Parscau 1991; MacBeth 1991a, b).

Interpretation In a classic paper, Mueller (1991) showed that the lateral variability of observed shear-wave splitting could be used to guide horizontal drilling into aligned fissures for enhanced oil recovery at depth in the Austin Chalk, TX, USA. This is one of the first published demonstrations of the direct value of azimuthally varying shear-wave splitting to the hydrocarbon industry.

Leary (1991) showed for the first time that both sonic and electrical resistivity well logs display fractal distributions for over three orders of magnitude of crack dimensions. Referred to as $1 / f$ noise, such effects have now been established as routinely present in virtually all well logs worldwide and are an important demonstration of the critical nature of cracks in the crust (Crampin 1998, 2003a, 2006; Crampin and Chastin 2001; Crampin et al. 2003). 
Liu et al. (1991), continuing the investigations of Queen and Rizer (1990), showed the effects of aligned fractures on shear-wave splitting in shallow VSPs at the Conoco Borehole Test Facility.

\subsection{IWSA, 1992, Banff, Canada: proceedings in Can. J. Expl. Soc., 29, 1993}

The Fifth International Workshop on Seismic Anisotropy was held in 1992 in Banff, Alberta, Canada (Table 1), with again the majority of papers in exploration seismics, this time with a significant number of case studies. The small number of earthquake studies included the first papers from mainland China. The proceedings of 5IWSA contain ten papers calculating synthetic seismograms (four of which directly model observed shear-wave splitting), and it is difficult to identify which of these papers is most significant for future developments. Note that, in the first 10 years of IWSAs, many of the original features of seismic anisotropy have now been discovered. This means that as time progresses there are smaller numbers of significant papers and it is more difficult to identify those papers which will be important for the future.

Theory Crampin (1993a) presented the arguments for distributions of microcracks (EDA cracks) rather than large cracks or fractures as the source of the nearly ubiquitous stress-aligned shear-wave splitting seen in almost all rocks. The evidence for microcracks has now recently been reviewed by Crampin and Peacock (2005). There are three key features that directly indicate microcracks: (1) the only anisotropy symmetry system with parallel polarisations is transverse isotropy with a horizontal symmetry axis (TIH anisotropy) or a minor perturbation thereof; (2) the only geological phenomenon with this symmetry is stressaligned microcracks; and (3) fluid-saturated cracks are the source of anisotropy that can display the observed rapid temporal changes. The overwhelming evidence for microcracks is that very similar phenomena are seen at all crustal depths in almost all rocks whose only common feature is the presence of stress-aligned fluid-saturated grain-boundary cracks in crystalline rocks and thin pores and pore throats in sedimentary rocks.
Although larger cracks clearly exist, propagation through distributions of larger cracks is likely to severely attenuate second split shear waves, as demonstrated by Mueller (1991), and cause reflections and refractions but not the ubiquitous shear-wave splitting. The overall conclusion is that most shear-wave splitting is caused by microcracks rather than macrocracks.

Crampin (1993b) gave a theoretical review of the effects of crack parameters on wave propagation through cracked solids. Note that there is no simple relationship between the degree of velocity anisotropy and crack density. Almost counterintuitively, the degree of velocity anisotropy and behaviour of both $P$ waves and shear waves is heavily dependent on crack aspect ratios, porefluid velocities and $V s$-to- $V p$ ratios (Poisson's ratio), as well as crack density. This means that unique inversions for crack parameters from observations of shear-wave splitting may be difficult if not impossible without very extensive datasets, which are seldom, if ever, available. There were several other papers about various anisotropic phenomena, including a number of papers about preferred techniques for observing or processing appropriate record sections.

Theory-synthetic seismograms Several 5IWSA papers calculated synthetic seismograms in cracked media with TIV anisotropy. Guest and Kendall (1993) used Maslov ray theory to calculate synthetic seismograms in anisotropic and inhomogeneous structures. Igel et al. (1993) presented a finite-difference grid technique which avoids problems with reflectivity (restriction to plane-layered models), ray techniques (limited heterogeneity) and finite difference (errors in phase and group velocities). The techniques of Igel et al. showed satisfactorily small relative errors but do not present synthetic seismograms. Leary et al. (1993) used finite-difference calculations of synthetic trapped-wave propagation in fractured low-velocity layers.

Wild et al. (1993) used ANISEIS to display instantaneous amplitude and polarisation attributes of synthetic VSPs in layered anisotropic structures (see note on ANISEIS in "Section 2.4"). Yao and Xiong (1993a, b) used the reflectivity technique of Booth and Crampin (1983) to model with 
synthetic seismograms radiation from an anisotropic point source and shear-wave splitting above local earthquakes. Zhang et al. (1993) used finitedifference modelling for synthetic seismograms in TIV.

Synthetic seismograms were also used to model observed shear-wave splitting. Gledhill (1993) used the reflectivity technique of Booth and Crampin (1983) through cracked structures (Hudson 1980, 1981) to match synthetic to observed shear-wave splitting in Wellington Peninsula, New Zealand. Liu et al. (1993a) used the ANISEIS software (Taylor 1990) to successfully match synthetic seismograms in a multiazimuth reverse VSP in the fractured Conoco Borehole Test Facility. Niitsuma et al. (1993) used wavelet transforms to model observed shearwave splitting in the Kakkonda geothermal area in Japan.

Observation and interpretation There were several unique observations confirming various anisotropic phenomena. Holmes et al. (1993) monitored shear-wave splitting in a sparse but nearly complete solid angle of directions in a granite batholith at an underground research laboratory. (Continuing analysis showed that excavation damage probably extended to at least three diameters from a 3-m-diameter tunnel, Holmes et al. 2000).

$\mathrm{Li}$ et al. (1993), continuing the analysis of Mueller (1991), showed that hydrocarbon production rates across the Austin Chalk, TX, USA, approximately correlated with degree of shear-wave splitting in reservoirs at two producing and one non-producing reservoir. This was a direct confirmation that varying degrees of shearwave splitting are directly correlated with variations in production.

Liu et al. (1993a), see above, successfully matched synthetic seismograms in a multiazimuth reverse VSP in fractured rock, confirming the association of shear-wave splitting to both micro- and macro-fracturing.

Liu et al. (1993b) monitored shear-wave splitting showing temporal variations, modelling stress accumulation, before a $M 4$ earthquake at Parkfield on the San Andreas Fault similar to variations reported previously (Peacock et al. 1988; Crampin et al. 1990; Booth et al. 1990).
This was the fourth example of a now frequently observed phenomenon. The third example was by Gao et al. (1998) on Hainan Island, China. Note that other papers at 5IWSA also searched for temporal changes in shear-wave splitting above small earthquakes.

Graham and Crampin (1993) examined regional earthquakes recorded by the TDP experiments in Turkey (Evans et al. 1987) and showed that shear-wave splitting in $\mathrm{Sn}$-waves, refracted along the Moho, indicate substantial crack-induced anisotropy in the lower crust with similar orientation as the upper crust but with larger time delays of up to $1 \mathrm{~s}$.

Observation-anisotropic cusps Slater et al. (1993) successfully modelled synthetic seismograms using ANISEIS software (Taylor 1990) in walkaway VSPs in an oil field in the Caucasus Basin, matching confirmed field observations of anisotropic cusps.

\subsection{IWSA, 1994, Trondheim, Norway: \\ proceedings on seismic anisotropy, Soc. Expl. Geophys., 1996}

The Sixth International Workshop on Seismic Anisotropy, 6IWSA, was in Trondheim, Norway (Table 1). The first paper was $A$ geophysicist's view on seismic anisotropy by Lynn (1996). The original earthquake stimulation for IWSA has now almost completely disappeared and Lynn made no mention of earthquake seismology. The next paper was by Helbig (1996) who, at several of the following IWSAs, presents papers outlining the historical background of seismic anisotropy. On this occasion, it was the contribution of William Thomson, later Lord Kelvin (1824-1907), to strain and stress tensors.

There were 20 other papers. Many of these were theoretical modifications of well-known phenomena, whose overall significance is difficult to assess. They included four papers on the theoretical modelling of anisotropic matrices, seven papers modelling wave propagation through material containing aligned cracks, several papers on various record-section processing techniques and several on rock mechanics experiments. 
Theory Rasolofosaon and Yin (1996) set up the equations for non-linearity (NL) in anisotropic elastic media and present rock mechanics results that suggest that the sensitivity of the NL response to changing parameters in anisotropy may be far greater than that of the linear parameters such as wave speeds and elastic moduli. This sensitivity was later to be confirmed in several papers (Angerer et al. 2002; Crampin et al. 2003; Volti and Crampin 2003b).

Observation and interpretation There were a small number of case studies. Horne et al. (1996) devised a successful genetic algorithm (GA) technique for inverting for elastic moduli for a $620-\mathrm{m}$ deep VSP at the Conoco Borehole Test Facility, whose shallow structure was modelled by Liu et al. (1991, 1993a). Kebaili et al. (1996) presented a new slant stack processing technique and successfully applied it to a shallow VSP in Alberta, and Stawicki and Lynn (1996) investigated the effects of complex tectonic strain on multi-azimuth VSPs in the Lower Indus Basin, Pakistan. Mjelde (1996) interpreted shear-wave velocities in the lower crust from two air-gun reflection surveys recorded on three-component ocean bottom seismographs at Lofoten, Norway, in terms of $14 \%$ shear-wave velocity anisotropy. This is one of the few examples, together with Graham and Crampin (1993) and Kaneshima (1990), of realistic estimations of lower-crustal shear-wave velocity anisotropy. Both Mjelde and Graham and Crampin agree that the azimuthal shear-wave velocity anisotropy in the lower crust may be over $10 \%$ and substantially higher than in the upper half of the crust.

\subsection{IWSA, 1996, Miami, FL, USA: proceedings in advances in anisotropy, Soc. Expl. Geophys., 2001}

The Seventh International Workshop on Seismic Anisotropy was held in Miami, FL, USA (Table 1). The meeting was now typical in that there were significant contributions on a wide range of topics that are too many to mention individually.

Theory - frequency dependent anisotropy Hornby (2001) found systematic differences between 'intrinsic' anisotropy of shales at ultrasonic frequency in cores with seismic-scale anisotropy in walkaway VSPs. The conclusion was that the effects of fine-layer anisotropy on the seismic scale are underestimated in sonic logs from the Dipole Shear Sonic Indicator borehole sonic tool.

Observation-laboratory Skjærstein and Fjær (2001) measured attenuation in the model of open fluid-saturated cracks of Rathore et al. (1995) which had been used to compare various theoretical models of cracks. They confirmed theoretical results that shear waves with polarisations perpendicular to parallel cracks are more attenuated than shear waves with polarisations parallel to the crack face (Crampin 1984b; Hudson 1981).

Theory-temporal changes Bokelmann (2001) presented a method for resolving small temporal variations between clusters of doublets (earthquakes with similar seismograms and similar source). The results showed that small temporal variations are common but Bokelmann offered no explanation. We can now suggest that the sensitivity of critical systems of fluid-saturated microcracks is a probable explanation (see papers in the next three IWSAs).

Observation and interpretation Two papers examined the effects of dipping TIV structures. Kühnel and Li (2001) developed an algorithm for separating anisotropy and structure from: a first-order isotropic dip term; two second-order residual terms, isotropic dip, dipindependent anisotropy; and one third-order dip- and anisotropy-dependent residual. The algorithm is usually effective except for particular orientations of the anisotropy of the matrix material, when the technique is no longer applicable. Leslie and Lawton (2001) propagated $P$-wave signals through an anisotropic laboratory model with structure simulating a dipping sequence of shales. Comparatively severe distortion can be interpreted in terms of anisotropic and dip parameters as long as the degree of anisotropy is not too great. 
2.9 8IWSA, 1998, Boussens, France: proceedings in spec. issue, Rev. Inst. Franc. Pet., 53, 1998

The Eighth International Workshop on Seismic Anisotropy was held in Boussens, France (Table 1). Approximately half the papers were on various aspects of theory and half on processing techniques but with very few case studies.

Theory Two papers calculated synthetic seismograms. Caddick et al. (1998) compared asymptotic- with Maslov-ray theory, which give different behaviour near shear-wave singularities. (Note that Crampin 1991 gave exact full-wave behaviour near singularities, using synthetic seismograms calculated by ANISEIS, Taylor 1987, 1990.) Chichinina and Oblentseva (1998) compared waveforms in anisotropic and gyrotropic media. Gyrotropy was not specifically defined but seems to refer to media with a continuous rotation of preferred shear-wave polarisations. As far as we know, such properties have not yet been demonstrated in elastic media nor in in situ rocks.

There were a number of papers presenting variations on standard procedures whose overall significance is difficult to judge. Helbig (1998) presented a formalism for the non-linearity suggested by Rasolofosaon and Yin (1996), and Chesnokov et al. (1998) developed a diagrammatic technique for the calculation of the dynamic properties, including the frequency response, of propagation through randomly distributed cracks and pores.

Observation Berthet et al. (1998) showed that imaging dipping structures was improved by anisotropic rather than isotropic post-stack processing. They demonstrated the improvement in a record section from offshore Africa.

Interpretation Raymer and Kendall (1998) showed synthetic seismograms through models containing salt, with anisotropic properties determined from laboratory texture analysis. They demonstrated that the anisotropy of salt produced substantial travel-time variations and significant shear-wave splitting that could be diagnostic of in situ salt.

Li (1998), assuming fracture-induced anisotropy, showed that near-vertically propagating converted $P S$ waves can indicate the orientation and intensity of in situ fractures. These effects were demonstrated with synthetic (ANISEIS) seismograms showing phase changes and variations in time delays.

Interpretation-critical systems Crampin (1998) suggested that the match of anisotropic poroelasticity (APE) modelling (Zatsepin and Crampin 1997; Crampin and Zatsepin 1997) to observed shear-wave splitting implies that the fluid-saturated stress-aligned microcracks in most rocks in the crust are so closely spaced that they are critical systems. This is now supported by a large variety of observations relating to cracks, stress and shear-wave splitting.

\subsection{IWSA, 2000, Camp Allen TX, USA: proceedings in anisotropy 2000 , Soc. Expl. Geophys., 2001}

The Ninth International Workshop on Seismic Anisotropy was held in Camp Allen, Houston, TX, USA (Table 1).

Theory Rommel and Tsvankin (2001) developed a simple analytical approach for group- and phasevelocity relationships for rays of $P$ waves in TIV and orthorhombic media, based on the notation of Tsvankin (1996) for the Thomsen (1986) parameters applied to orthorhombic media. Helbig and Rasolofosaon (2001), continuing the work of Rasolofosaon and Yin (1996), developed a formalism for incorporating non-linearity and hysteresis into a "unifying theory". Garmany (2001) showed analytically that phase shifts $\left(90^{\circ}\right.$ flips) in shear-wave polarisations occur whenever a ray touches a caustic surface (or passes near a shear-wave singularity as demonstrated with synthetic full-wave seismograms by Crampin 1991).

Theory-AVOs and fractures There were eight papers dealing with various aspects of processing Amplitude Variations with Offset (AVOs) of models with anisotropic-layered structure containing fractures. All seem useful, but space restrictions limit comments to two papers. Ikelle and Amundsen (2001) presented preliminary 
techniques for interpreting $P-P, P-S V$ and $P-S H$ data with the ambiguity of TIV anisotropy and heterogeneity. Since anisotropy and heterogeneity may always be present in AVOs, these techniques could be important discriminants. Liu et al. (2001) presented techniques for extracting information about crack compliance and porefluid parameters from AVO analysis. Using synthetic seismograms, Liu et al. showed that the combined use of AVOs of $P-P$ and $P-S V$ waves offers advantages in determining fractures and fluid saturations.

Observation-case studies There were two case studies. Granger et al. (2001) used the shear-wave splitting of $P$-to- $S$-converted waves ( $C$ waves) recorded on 3D-4C ocean bottom geophones to make a preliminary evaluation of azimuthal anisotropy of the North Sea Valhall Field. Results showed that principal directions coincide with fault systems at two levels from this feasibility demonstration, but the authors do not attempt any interpretive conclusions. Berthet et al. (2001) applied anisotropic pre-stack depth migration to offshore data in West Africa. The technique showed sufficient sensitivity that can be used as a lithology discriminate to detect isotropic sands of a few wavelengths thickness.

Interpretation-processing TIV media Five papers described various techniques for processing TIV media. We shall only refer to Williamson and Maocec (2001) who estimated local anisotropy using polarisations and travel times from the Oseberg 3D VSP. They achieved better determination of anisotropy by inverting polarisations than by standard slowness inversion.

Interpretation-critical systems Crampin and Chastin (2001) claimed that three recent results support the arguments of Crampin (1998) that the stress-aligned fluid-saturated microcracks in almost all rocks are so closely spaced that they are critical systems. The papers reported: modelling the response of a reservoir to a high-pressure fluid injection (published later by Angerer et al. 2002); modelling frequency dispersion in laboratory experiments (published later in Chapman et al. 2002); and a successfully stress-forecast earthquake (Crampin et al. 1999). It is suggested that critical systems of stress-aligned fluid-saturated microcracks are the physical reality underlying the well-known self-organised criticality of the Gutenberg and Richter relationship. They also have a profound effect on a wide range of solid earth geoscience including carbon production and earthquake science (Crampin 2006).

\subsection{IWSA, 2002, Tutzing, Germany: proceedings in spec. issue, J. Appl. Geophys., 54, 2003}

The Tenth International Workshop on Seismic Anisotropy, 10IWSA, 2002, was in Tutzing, Germany (Table 1). There were too many useful and interesting papers at this meeting to refer to each individually.

Theory-shear-wave triplication Thomsen and Dellinger (2003) discussed analytically the occurrence of cusps and shear-wave triplications and suggest that $P$-wave kinematics indicate that cusps in the $S V$-wave sheet in TIV anisotropy are common. Although such triplications have been observed in a wide-angle VSP (Slater et al. 1993), the angles of incidence at which cusps would be seen are further from the vertical than typical $P$-to- $S$-converted waves (C waves) as would usually be sampled in surface seismic surveys.

Theory and observation-frequency-dependent anisotropy Gurevich (2003) developed the mathematics for the elastic properties of saturated porous rock with aligned cracks. Wave-induced fluid flow between pores and cracks in rock with parallel cracks was shown to alter the elastic behaviour for low-frequency waves. Chapman et al. (2003) showed that the movement of fluids between cracks and pore space strongly alters the anisotropic behaviour, where a simplified model matched laboratory data. In particular, the analysis showed the effects are frequency dependent. Li and Yuan (2003) derived improved equations for calculating the moveout and conversion points of the non-hyperbolic $\mathrm{C}$ waves. Comparison of analysis with real data shows that the technique is sufficiently accurate to yield reliable structures. 
Liu et al. (2003) observed and interpreted frequency-dependent anisotropy in terms of variations of time delays with depth in different frequency pass bands. The anisotropy diminished from $28 \%$ at $10 \mathrm{~Hz}$ to $2 \%$ at $25 \mathrm{~Hz}$.

Observation and interpretation Gao and Crampin (2003) reported temporal variations of shear-wave splitting in field and laboratory studies in China, which show changes of shearwave splitting with increasing stress and pressure. The laboratory experiments show an abrupt decrease in time delays immediately before fracturing occurs. Such stress relaxation is also observed before earthquakes (Gao and Crampin 2004), where it is now interpreted as the effects of crack coalescence as the impending fracture is identified in the fluid-stress evolution.

Observation and interpretation-critical system sensitivity Crampin et al. (2003; see also Crampin 2004) reported preliminary results from a prototype borehole Stress-Monitoring Site (SMS) adjacent to the Húsavík-Flatey Transform Fault in Northern Iceland. Well-recorded anomalies (accurate to $\pm 0.02 \mathrm{~ms})$ in $P, S H, \mathrm{SV}$ travel times and shear-wave splitting ( $S V-S H$ travel times) correlated with low-level seismicity (equivalent energy to one $M 3.5$ earthquake) at $70-\mathrm{km}$ distance. This exceptional sensitivity (in layered basalts), at hundreds of times the conventional source dimensions, confirms the criticality of the fluid-saturated microcracks in the crust as advocated by Crampin (1998) and Crampin and Chastin (2001). Crampin et al. (2003) also reported $90^{\circ}$ flips in shear-wave polarisations caused by critically high pore-fluid pressures on all seismically active faults (Crampin et al. 2002). These $90^{\circ}$ flips are the cause of the large $( \pm 80 \%)$ scatter in shear-wave splitting time delays (Crampin et al. 2004) invariably observed above small earthquakes (Crampin et al. 1990; Booth et al. 1990).

2.12 11IWSA, 2004, St. Johns, Newfoundland, Canada: no published proceedings, but abstracts in Geophysics, 71, 13JF-29JF, 2006

The 11th International Workshop on Seismic Anisotropy, 11IWSA, was in St John's, New- foundland, Canada (Table 1). This meeting had the largest attendance of any IWSA. The majority of the abstracts at 11IWSA was theoretical and appears to be modifications of well-known phenomena. At this time, it is difficult to judge their future relevance.

Theory-frequency-dependent anisotropy Vikhorev et al. (2006) suggest that different scales of inhomogeneities can cause differences between the values of anisotropy in 'sonic waves' ( $\sim 20 \mathrm{kHz})$ and 'seismic waves' $(5-10 \mathrm{~Hz})$.

Theory-wave propagation in viscoelastic media Červený and Pšenčík (2006) investigate the properties of plane waves in viscoelastic anisotropic media by specifying the attenuation by complex values of the slowness vector. Note that the use of complex elastic moduli for modelling attenuation was suggested by Crampin (1981), and ANISEIS routinely uses complex moduli to model full-wave synthetic seismograms in multi-layered attenuating media (Taylor 1990). In some ways, complex moduli may be a more natural way to specify attenuating media, as one complex specification of the media avoids the complications of the complex slowness of Červený and Pšenčík (2005, 2006).

Theory-wave propagation in penny-shaped cracks - a necessary correction Grechka (2006) uses finite-element modelling to determine Thomsen parameters for media with parallel cracks and shows results that diverge from those of Hudson (1980), particularly for crack densities greater than 0.05 . Grechka attributes the divergence to the first-order theory of Hudson (1980, 1981) not treating crack-to-crack interactions. This is not surprising. Hudson (1980, 1981) is a first-order theory. The second-order theory of Hudson (1986) correctly models crack-to-crack interactions. Grechka also claims that "conventional wisdom" suggests Hudson's "first-order results are correct up to crack densities $\approx 0.1$ ". Conventional wisdom is incorrect. Microcrack densities in stable unfractured rock are limited to less than the fracture criticality of $\sim 0.05$ (Crampin 1994, 1999; the exact values may vary slightly with different matrix Poisson's ratios 
and different fluid properties Crampin 1993b). This is not a question of formulaic derivation or mathematical modelling. The physical reality of crack densities of aligned cracks higher than $\sim 0.05$ is that the rock is so heavily fractured that it is without shear strength and is physically unstable if the external constraints are relaxed in any way. Hudson's $(1980,1981,1986)$ formula are valid for parallel cracks with crack-to-crack interactions in stable rock for crack densities less than the physical limitation of $\sim 0.05$.

Observation- $\mathrm{CO}_{2}$ injections Jenner (2006) investigates the effects of injecting high-pressure $\mathrm{CO}_{2}$ at $10-14 \mathrm{MPa}$ on the anisotropic behaviour of $P$ waves in a reservoir at the Weyburn Field, Saskatchewan, Canada and finds that there is no "seismically discernible change in anisotropy". Note that Angerer et al. (2002), who found substantial changes in shear-wave anisotropy for similar high-pressure $\mathrm{CO}_{2}$ injections, also found negligible changes in P-wave signals. Theory and observations suggest that the principal effect of changing pressures is to modify crack aspect ratios (Crampin 1999). Nearly-vertically propagating $P$ waves are not very sensitive to aspect ratios of nearly-vertically aligned cracks. Jenner (2006) confirms that shear-wave splitting is the most sensitive phenomenon for time-lapse monitoring of small changes in conditions.

Interpretation-GEMS, the opportunity for a global network of borehole stress-monitoring sites to forecast all damaging earthquakes worldwide Crampin et al. (2005) suggest that the sensitivity of the prototype borehole stress-monitor site (Crampin et al. 2003) indicates that a global network of (both onshore and offshore) borehole SMSs, on a $400-\mathrm{km}$ grid in seismic areas and a $1,000-\mathrm{km}$ grid elsewhere, would be able to forecast all damaging earthquakes $(M \geq 5)$ worldwide.

\subsection{IWSA, 2006, Beijing, China: proceedings} in press in Journal of Seismology and Journal of Seismic Exploration. We refer to 12IWSA expanded abstracts, 2006

The 12th International Workshop on Seismic Anisotropy, 12IWSA, was held in Beijing, China
(Table 1). This was the largest IWSA meeting, with $\sim 60$ national and 60 international participants, 59 oral presentations and 53 posters, with significant advances in theory, observation and interpretation. 12IWSA in Beijing stimulated a significant input from China. There were 15 oral presentations and 37 posters where the lead author was from China and many more from Chinese nationals working abroad.

There were three entertaining and informative invited Keynote Addresses: Leon Thomsen discussed the various levels of anisotropy and symmetry; Heloise B. Lynn discussed the present and future of anisotropy in exploration seismics; and Savage (2006) discussed anisotropy from the inner core to the crust with particular reference to New Zealand.

There were a large range of abstracts on theory, observation and interpretation, with far too many for detailed description. Only overall trends and a few key contributions can be noted. For example, there were 11 abstracts describing various techniques for removing the effects of VTI anisotropy, transverse isotropy with a vertical axis of symmetry. (Note that VTI now appears to be the agreed mnemonic for what is also called TIV anisotropy.) There were also seven abstracts on processing and analysing "Tilted Transverse Isotropy" or TTI a comparatively frequent occurrence in reservoirs where fine layering is not horizontal. One general problem with many of these processing techniques is that the effects are a better resolved "anisotropy" but there is little interpretation of what the anisotropy means, other than the rather vague supposition that the anisotropy refers to unresolved 'fractures'.

Theory The most important theoretical advance at 12IWSA was probably the virtual source method (VSM) suggested by Bakulin and Calvert (2006) where a virtual shear-wave source can be constructed at downhole geophones by time reversal and deconvolution with the signals from surface sources. This effectively places sources at downhole geophone positions and eliminates the highly heterogeneous near-surface effects. VSM is believed to have great value for constructing shear-wave signals propagating through deeper layers. 
Observation The Common Offset-Common Azimuthal (COCA) Cube of Gray (2006) is an effective way of displaying pre-stack seismic data that highlight azimuthal anisotropy. Just as the Common Offset Stack serves as a quality control and visual confirmation of AVO anomalies, the COCA Cube serves as a visual quality control of azimuthal anisotropy attributes.

Interpretation-attenuation Several interpretations gave direct information about the subsurface. Chapman (2006) showed that $P$-wave attenuation anisotropy in a fractured layer is a better indicator of fractures than $P$-wave traveltime anisotropy and can potentially provide new information about fracture dimensions and fluid content. Chapman hopes to develop interpretation of shear-wave anisotropy in the future.

Interpretation-kinematic and dynamic anisotropy As an example, Liu et al. (2006) showed theoretically that kinematic anisotropy (traveltime- and velocity-based measurements) and dynamic anisotropy (amplitude and attenuation measurements) may have different symmetries when there are two crack sets with different fluid contents (dry and brine-filled, say). These different symmetries have measurable effects on seismograms. This means that differences between different field measurements potentially contain valuable information about complex stress-fluid fracture systems.

Interpretation-the New Geophysics Crampin and Gao (2006b) argue that worldwide observations of shear wave indicate that the stress-aligned fluid-saturated microcracks causing the splitting are so closely spaced that they verge on fracture criticality and fracturing and are critical systems with all that that implies (Crampin 1998, 2003a, 2004, 2006; Crampin and Chastin 2001). Below criticality, critical systems of complex interactive heterogeneous phenomena act locally and have complicated reactions to local heterogeneities. However, at criticality, the whole system abruptly acts in unison. It is said to be "one of the universal miracles of nature" that at critical points whole assemblages of elements "are capable of organising themselves into patterns of cooperative activity" (Davis 1989).

Critical systems have several crucial differences from conventional geophysics:

1. Behaviour near criticality is calculable so that seemingly complicated overall phenomena may be calculated by simplified effects neglecting detailed behaviour, hence the "unreasonable" success of APE modelling. This may be the reason why the Gassmann Theory is apparently applicable outside the expected range (Rasolofosaon 2006).

2. There is extreme ("butterfly wing's") sensitivity to seeming negligible changes (see Crampin et al. 2003, Rasolofosaon and Yin 1996). These two effects mean that low-level deformation can be monitored with shearwave splitting and calculated (predicted) with APE.

3. Since the behaviour is calculable, as demonstrated by Angerer et al. (2002), then any desired level of cracking, as imaged by shearwave splitting, can be potentially controlled. If the desired effects are not achieved, they can be adjusted by feedback (Crampin 2006). This 'New Geophysics' is fundamentally different from conventional sub-critical geophysics and has such potentially important applications, where shear-wave splitting is the key observable that the future of IWSA meetings seems assured.

4. One of the consequences of the New Geophysics of crack-critical systems is that universality (Davis 1989; Bruce and Wallace 1989) tends at apply over the full range of appropriate phenomena. Since a very similar range of shear-wave splitting parameters is found both in the crust and upper mantle and hydrated melt is expected, in at least some circumstances, in the upper mantle, the universal character of critical systems suggests that fluid-saturated cracks, where the in-fill is hydrated melt, may contribute to shear-wave anisotropy in the upper mantle (Crampin 2003b). Crack anisotropy in the upper mantle was originally suggested by Ando et al. (1980, 1983). 


\section{Discussion and conclusions}

There have been some 250 papers published in the proceedings of 0IWSA to 11IWSA (part of proceedings of 12IWSA is published in this issue). This review cites papers from IWSA proceedings, which are believed to be significant for the continuing development of shear-wave splitting and seismic anisotropy, usually because they were first observations, first analyses or important leads to the continuing developments. With ten or more years' hindsight, one can recognise the significant papers. Recent papers tend to be smaller advances over broader fronts, whose significance is more difficult to assess. Consequently, this review is necessarily a rather subjective selection, and there are many excellent papers in the recent proceedings that are too numerous to cite individually, and we beg forgiveness of those authors whose papers have been omitted.

What are believed to be the most significant advances are summarised in Table 2. Each IWSA tends to be unique with the principal subject matter changing from one workshop to the next. Almost all significant developments in crustal shear-wave splitting have appeared in IWSA proceedings, and most of the few papers published elsewhere have been cited in this review. One of the principal benefits of IWSA workshops has been that all the major research workers in anisotropy have known (and trusted) each other. Consequently, workshops have been comparatively open, so that most impending developments have been immediately known to the whole research community of 'anisotropists'. This has meant that frequently, without prior consultation, several, sometimes many, people work on similar topics, so that IWSA meetings often have a dominating topic of research. This has no doubt contributed to the comparatively rapid advance, for a fundamentally new concept, which has taken anisotropy, particularly shear-wave splitting, from the first occasional observations in the crust, to observations worldwide, and an understanding of fluid-rock deformation in a critical system of closely spaced fluid-saturated microcracks in almost all rocks in the Earth's crust.

Note that the Society of Exploration Geophysicists (SEG) has promoted much of the research in seismic anisotropy and shear-wave splitting. Its own annual meetings have had many sessions on anisotropy. It has sponsored several IWSAs and has published proceedings or abstracts of several IWSAs (Table 1). SEG awarded three Virgil Kauffman Gold Medals for research in anisotropy (Stuart Crampin in 1988; Richard M. Alford in 1990; Ilya Tsvankin in 1996). Leon Thomsen (2002) presented a Distinguished Short Course on anisotropy, and Lynn (2004) was Distinguished Lecturer on anisotropy. Leon Thomsen is currently President of SEG-an honour for Thomsen and also perhaps for anisotropy and IWSA.

Note also that Joe Dellinger of BP maintains an Internet email address where information can be posted on an Anisotropists Digest list. This greatly aids communication between 'anisotropists', who register at $<$ anisotropists-request@freeusporg $>$.

IWSAs have reported observations of, particularly, shear-wave splitting, with very similar characteristics over an enormous range of frequencies from the upper mantle $(0.05-0.5 \mathrm{~Hz})$ in surface-wave studies, above crustal earthquakes $(2-20 \mathrm{~Hz})$, reflection seismology $(10-80 \mathrm{~Hz})$, VSPs $(10-200 \mathrm{~Hz})$, sonic logs $(\mathrm{kHz})$ and laboratory measurements $(\mathrm{MHz})$. Since such universality and calculability are characteristic of critical systems (Davis 1989; Bruce and Wallace 1989), these are comparatively direct evidence for critical systems of fluid-saturated cracks as extensive all-embracing phenomena (Crampin and Chastin 2001; Crampin et al. 2003; Crampin and Gao 2006b; Crampin 2006).

As Vikhorev et al. (2006) suggested, anisotropy covers an enormous range of lineament dimensions, and indeed, as Heffer and Bevan (1990) observed, the frequency and lengths of microcracks, cracks, fractures, faults and lineaments are self-similar over some ten orders of magnitude. This is related to the other outstanding self-similar distribution in geophysics, the Gutenberg-Richter relationship between frequency and magnitude of earthquakes, over some eight orders of magnitude. Consequently, we recognise that the deformation of fluid-saturated cracks is the physical reality underlying the Gutenberg-Richter relationship. This had been suspected in the past (Turcotte 1992), but this is now a direct correlation with other phenomena. 
Table 2 Summary of significant advances in seismic anisotropy at IWSA meetings

\begin{tabular}{|c|c|c|c|}
\hline ID & Year of IWSA & Year of proceedings & Significant advances \\
\hline \multicolumn{4}{|c|}{ OIWSA-3IWSA: principally earthquake seismology } \\
\hline \multirow[t]{4}{*}{ OIWSA } & 1975 & 1977 & $\begin{array}{l}\text { Synthetic seismograms in anisotropic layered models } \\
\text { (Keith and Crampin 1977a, b, c) }\end{array}$ \\
\hline & & & $\begin{array}{l}\text { Anisotropy observed in upper mantle from } P n \text {-wave velocity } \\
\text { anisotropy beneath both oceans (Hess 1964) and continents } \\
\text { (Bamford 1977) }\end{array}$ \\
\hline & & & $\begin{array}{l}\text { Anisotropy observed (Crampin 1966) and calculated in higher-mode } \\
\text { surface-wave dispersion (Crampin and King 1977) }\end{array}$ \\
\hline & & & $\begin{array}{l}\text { Shear-wave splitting first named (as } S \text {-wave splitting) and displayed in } \\
\text { synthetic seismograms (Keith and Crampin 1977c) }\end{array}$ \\
\hline \multirow[t]{7}{*}{ 1IWSA } & 1982 & 1984 & $\begin{array}{l}\text { Observations of } P \text {-wave velocity anisotropy in field and laboratory } \\
\text { (Artemieva and Chesnokov 1991; Brodov et al. 1991; Brown et al. } \\
\text { 1991; de Parscau 1991; MacBeth 1991a, b) }\end{array}$ \\
\hline & & & Elastic moduli calculated for aligned cracks (Crampin 1978, 1984b) \\
\hline & & & $\begin{array}{l}\text { Importance of shear-wave window above small earthquakes } \\
\text { recognised (Evans 1984) }\end{array}$ \\
\hline & & & $\begin{array}{l}\text { Aligned microcracks (EDA cracks) suggested in most crustal rocks } \\
\text { (Crampin et al. 1984b) }\end{array}$ \\
\hline & & & $\begin{array}{l}\text { General behaviour of wave propagation in cracked media reviewed } \\
\text { (Crampin 1981) }\end{array}$ \\
\hline & & & $\begin{array}{l}\text { Shear-wave splitting displayed in synthetic seismograms through } \\
\text { cracked media (Crampin 1978) }\end{array}$ \\
\hline & & & $\begin{array}{l}\text { Shear-wave splitting observed above earthquakes in both crust } \\
\text { (Crampin et al. 1980) and upper mantle (Ando et al. 1980) }\end{array}$ \\
\hline \multirow[t]{4}{*}{ 2IWSA } & 1986 & 1987 & $\begin{array}{l}\text { Observations of } P \text {-wave anisotropy in crust (Leary et al. 1987; } \\
\text { Li et al. 1987; Galperina and Galperin 1987) }\end{array}$ \\
\hline & & & $\begin{array}{l}\text { Speculation on how monitoring shear-wave splitting could predict } \\
\text { earthquakes (Chen et al. 1987) }\end{array}$ \\
\hline & & & $\begin{array}{l}\text { Determination of the Thomsen parameters for seismic exploration } \\
\text { (Thomsen 1986) }\end{array}$ \\
\hline & & & $\begin{array}{l}\text { Double-contour integration for 3D full-wave propagation in } \\
\text { anisotropic substrates (Taylor 1987) }\end{array}$ \\
\hline \multirow[t]{5}{*}{ 3IWSA } & 1988 & 1990 & $\begin{array}{l}\text { Observations of anisotropy in laboratory studies in both field and } \\
\text { laboratory (Kaneshima 1990; Li et al. 1990; Savage et al. 1990; } \\
\text { Shih and Meyer 1990) }\end{array}$ \\
\hline & & & $\begin{array}{l}\text { First attempts at automatic measurement of shear-wave splitting } \\
\text { (Shih and Meyer 1990) }\end{array}$ \\
\hline & & & $\begin{array}{l}\text { First correlation of microcracks with fractures and directions of } \\
\text { preferred fluid flow (Queen and Rizer 1990) }\end{array}$ \\
\hline & & & $\begin{array}{l}\text { Shear-wave splitting time delays seen to increase before two } \\
\text { earthquakes (Booth et al. 1990; Crampin et al. 1990) }\end{array}$ \\
\hline & & & $\begin{array}{l}\text { ANISEIS programme developed for applying double-contour } \\
\text { integration for full-wave synthetic seismograms through } \\
\text { anisotropic layered models (Taylor 1990) }\end{array}$ \\
\hline \multicolumn{4}{|c|}{ 4IWSA-12IWSA: Principally exploration seismology } \\
\hline \multirow[t]{4}{*}{ 4IWSA } & 1990 & 1991 & $\begin{array}{l}\text { First } 10 \text { years of shear-wave splitting reviewed } \\
\quad \text { (Crampin and Lovell 1991) }\end{array}$ \\
\hline & & & $\begin{array}{l}\text { Review of theory of wave propagation in aligned cracks } \\
\text { (Hudson 1991) }\end{array}$ \\
\hline & & & $\begin{array}{l}\text { Shear-wave singularities: identified in cracked VTI anisotropy } \\
\text { (Wild and Crampin 1991) }\end{array}$ \\
\hline & & & Synthetic seismograms of shear-wave singularities show \\
\hline
\end{tabular}


Table 2 (continued)

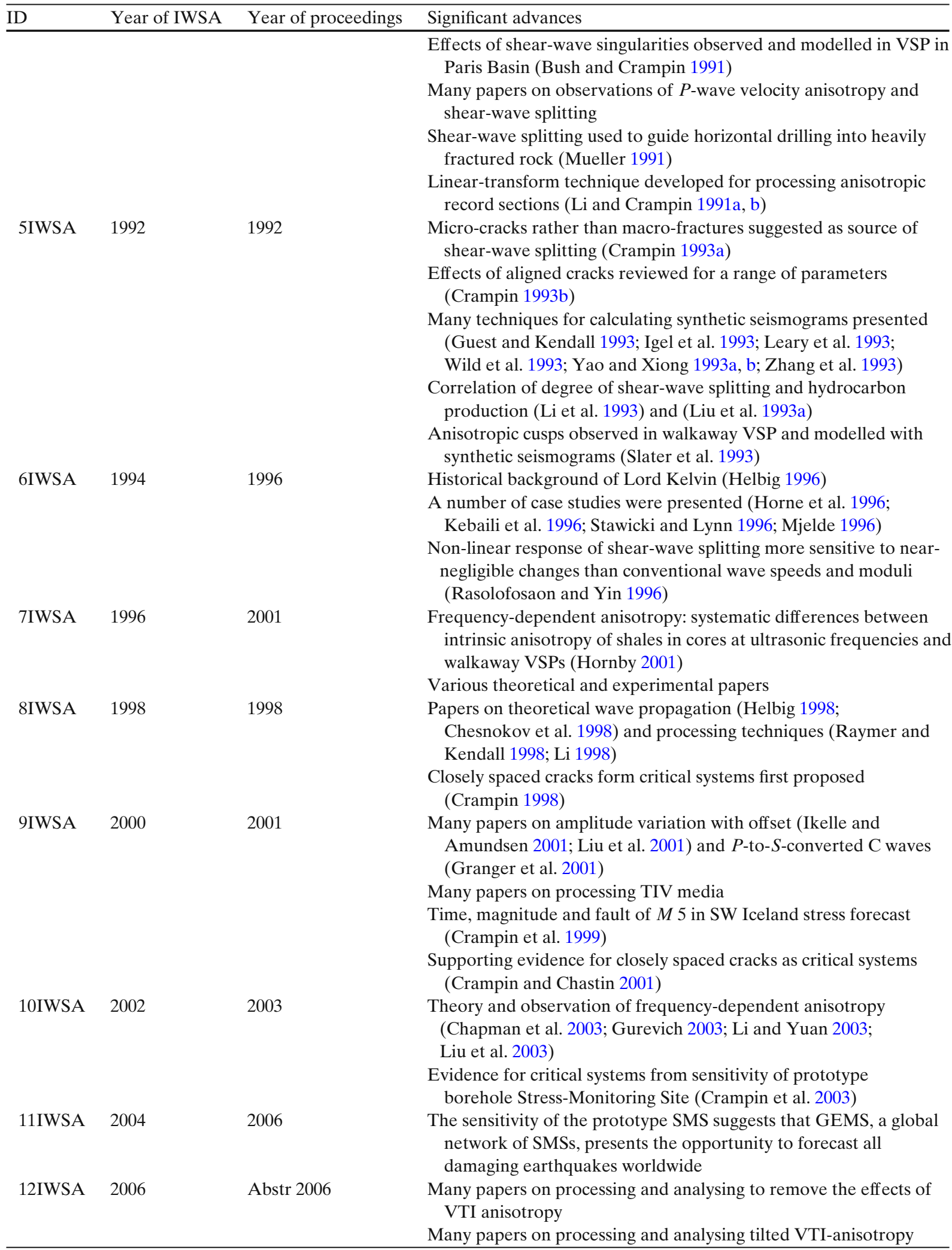


Table 2 (continued)

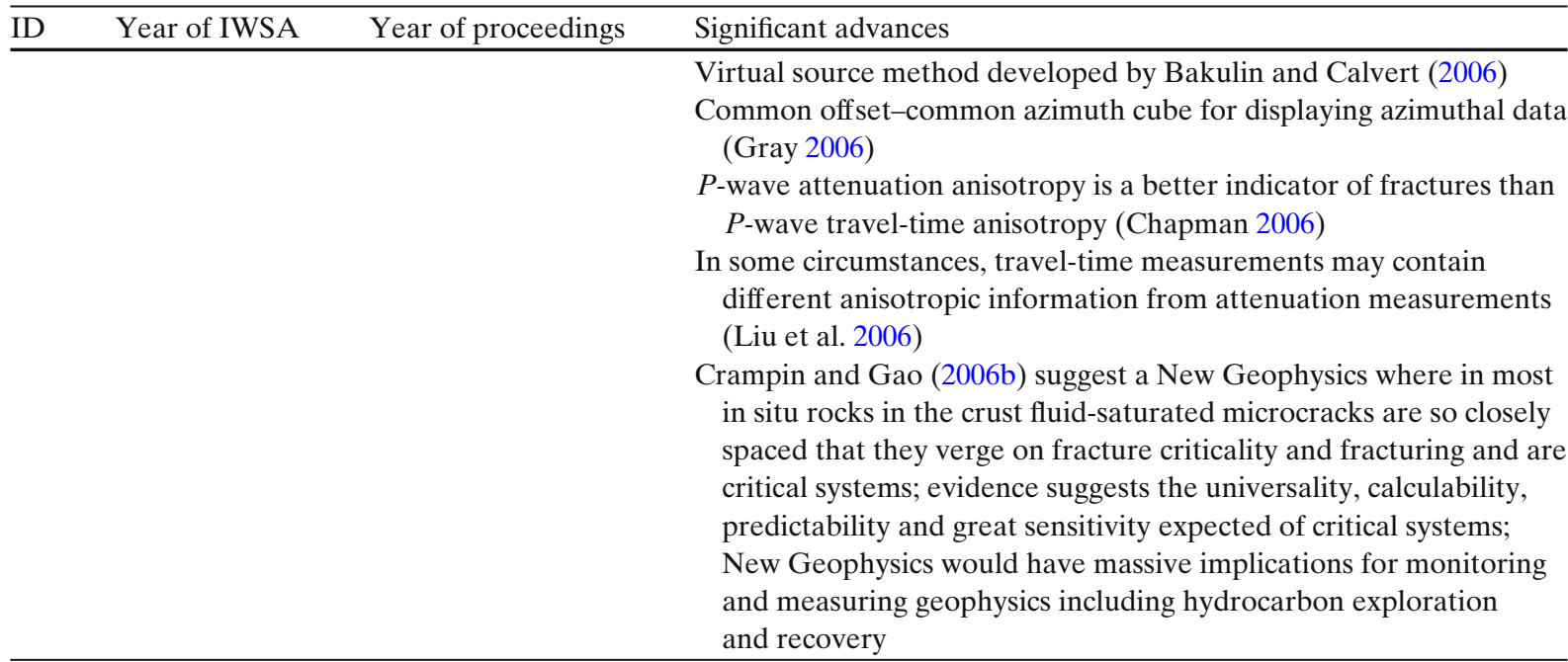

In the earth, there is a continuum of all scales of ordered heterogeneities, from $0.01 \mathrm{~mm}$ of microcracks to $100 \mathrm{~s}$ of kilometre plate boundaries in critical systems. The implications of critical systems are that low-level deformation before fracturing takes place: can be monitored with shear-wave splitting; future behaviour calculated by APE; even predicted if changing conditions are known, as in Angerer et al. (2002); and in some circumstances future behaviour potentially controlled by feedback (Crampin 2006). If correct, and the papers at this series of IWSAs reported in this review suggests overwhelming evidence that it is correct, this is such a fundamental advance in understanding fluid-rock (pre-fracturing) deformation in solid Earth geoscience that it is a New Geophysics.

A large proportion of papers by exploration seismologists presented at IWSAs have been about observing, processing and calculating the effects of anisotropy and shear-wave splitting, with much of the emphasis on how anisotropy effects conventional isotropic processing: how conventional processing for structure and stratigraphy is affected by anisotropy. The New Geophysics suggests that the implications of shear-wave anisotropy for fluid-rock interaction are likely to be crucially important for hydrocarbon production in the future, as well as almost all other solid earth geoscience, by their effects on fluid-rock deformation.
Acknowledgements We thank Klaus Helbig, Sheila Peacock, Ivan Pšenèík, Michael Slawinski and Leon Thomsen for information about IWSA workshops that neither of the authors attended. We particularly thank Heloise Lynn for her valuable comments. We also thank the Guest Editor Martha Savage and Yong-Gong Li, whose meticulous comments greatly improved the manuscript. YG was supported by NSFC Project: 40674021.

\section{Appendix: how IWSAs began}

Evgeni Chesnokov and Stuart Crampin, in a casual conversation over a vodka-fuelled dinner during a 3-month collaboration in Moscow in the winter of 1979-1980, speculated on the need for an international workshop on seismic anisotropy to discuss and publicise our ideas. In those days, anisotropy needed encouragement. Several eminent geophysicists (who shall be nameless) poured scorn on the very idea of widespread stressaligned anisotropy in the Earth. Evgeni and I needed to gather support to show we were not wasting our time. One of us (EC) happened to mention this idle speculation to Academician V.A. Magnitsky, who immediately lent his authority to the idea, and the workshop was on its way. Organised by Chesnokov, Crampin and Magnitsky, the first IWSA was in 1982 in the beautiful ancient city of Suzdal, USSR.

The workshop happened to be in the right place at the right time. Shear-wave splitting had just 
been reported both in the crust and upper mantle, and there was more general interest in anisotropy in USSR than elsewhere at that time.

1IWSA set the pattern for future IWSAs. IWSAs tend to be comparatively small (less than 100 participants) and single session, tend to be in interesting and memorable places and tend, after 2IWSA, to alternate across the Atlantic (and now the Pacific). IWSAs have been from Monday to Friday, with Wednesday set aside for the usually cultural excursions. These excursions are important since many of the most productive ideas, as with the original idea for IWSA, come from casual exchanges away from the seminar room.

The first IWSA, in 1982, was a resounding success and seemed worth continuing, so the next meeting was arranged 4 years hence in Moscow, 1986. This gap set another pattern. After 2IWA, biennial meetings were established. IWSAs are not repeated unless there is sufficient enthusiasm amongst participants at one meeting to organise the next in 2 years time. Thus, IWSA meetings have built-in quality assurance. When enthusiasm flags, IWSAs will immediately fold, which will be a right and proper finale to what has been a productive and rewarding series of meetings.

Note added in proof Papers from Proceedings of IWSA workshops are indicated by asterisks.

\section{References}

Alford RM (1986) Shear data in the presence of azimuthal anisotropy: Dilley, Texas. In: 56th ann int soc expl geophys mtg, Houston, expand abst, pp 476-379

Ando M, Ishikawa Y, Wada H (1980) S-wave anisotropy in the upper mantle under a volcanic area in Japan. Nature 286:43-46

Ando M, Ishikawa Y, Yamazaki F (1983) Shear wave polarisation anisotropy in the upper mantle beneath Honshu, Japan. J Geophys Res 88:5850-5864

Angerer E, Crampin S, Li X-Y, Davis TL (2002) Processing, modelling, and predicting time-lapse effects of overpressured fluid-injection in a fractured reservoir. Geophys J Int 149:267-280

*Artemieva IM, Chesnokov EM (1991) Thermal characteristics of anisotropic media with inclusions. Geophys J Int 107:557-562

Aster RC, Shearer PM, Berger J (1990) Quantitative measurements of shear-wave polarizations at the Anza seismic network, Southern California: implications for shear wave splitting and earthquake prediction. J Geophys Res 95:12449-12473

Aster RC, Shearer PM, Berger J (1991) Reply to Crampin S, Booth DC, Evans R, Peacock S, Fletcher JB. J Geophys Res 96:6415-6419

*Babuška V (1984) P-wave velocity anisotropy in crystalline rocks. Geophys J R Astron Soc 76:113-119

*Babuška V, Pros Z (1984) Velocity anisotropy in granodiorite and quartzite due to the distribution of microcracks. Geophys J R Astron Soc 76:121-127

*Bakulin A, Calvert R (2006) Renaissance of shearwave seismic by virtual source method. In: 12IWSA, expand abst, pp 88-89

*Bamford D (1977) Pn velocity anisotropy in a continental upper mantle. Geophys J R Astron Soc 49: 29-48

*Bamford D, Crampin S (1977) Seismic anisotropythe state of the Art. Geophys. J R Astron Soc 49: $1-8$

*Berthet P, Williamson P, Sexton P, Le Rousseau J (1998) 3D anisotropic post stack imaging on an offshore Africa case study. Rev Inst Fr Pet 53:547-553

*Berthet P, Williamson P, Sexton P, Mispel J (2001) Anisotropic prestack depth migration: an offshore Africa case study In: Ikelle L, Gangi A (eds) Anisotropy 2000. Soc expl geophys, open file publ, vol 6. pp 69-75

*Bokelmann GHR (2001) A method for resolving small temporal variations of effective elastic properties. In: Hood JA (ed) Advances in anisotropy, selected theory, modeling, and case studies. Soc expl geophys, open file publ, vol 5. pp 85-97

Booth DC, Crampin S (1983) The anisotropic reflectivity theory. Geophys J R Astron Soc 72:755-766

Booth DC, Crampin S (1985) Shear-wave polarizations on a curved wave front at an isotropic free-surface. Geophys J R Astron Soc 83:31-45

*Booth DC, Crampin S, Chesnokov EM (1987) Preface in proceedings of the second international workshop on seismic anisotropy. Geophys J R Astron Soc 91: 261-263

*Booth DC, Crampin S, Lovell JH, Chiu J-M (1990) Temporal changes in shear wave splitting during and earthquake swarm in Arkansas. J Geophys Res 95: 11151-11164

*Brodov LY, Tikkonov AA, Chesnokov EM, Tertychnyi VV, Zatsepin SV (1991) Estimating physical parameters of cracked-porous oil reservoirs by inverting shear-wave splitting. Geophys J Int 107:429-432

*Brown RJ, Lawton DC, Cheadle SP (1991) Scaled physical modelling of anisotropic wave propagation: multioffset profiles over an orthorhombic medium. Geophys J Int 107:693-702

Bruce A, Wallace D (1989) Critical point phenomena: universal physics at large length scale. In: Davis $\mathrm{P}$ (ed) The new physics. Cambridge University Press, Cambridge, pp 236-267

*Bush I, Crampin S (1991) Paris basin VSPs: case history establishing combinations of matrix- and crackanisotropy from modelling shear wavefields near point singularities. Geophys J Int 107:433-447 
Byerly P (1938) The earthquake of July 6, 1934: amplitudes and first motion. Bull Seism Soc Am 28:1-13

*Caddick J, Kendall JM, Raymer DG (1998) Maslov shearwaveforms in highly anisotropic shales and implications for shear-wave splitting analysis. Rev Inst Fran Pet 53:629-642

*Červený V, Firbas P (1984) Numerical modelling and inversion of travel times of seismic body waves in inhomogeneous anisotropic media. Geophys J R Astron Soc 76:41-51

Červený V, Pšenčík I (2005) Plane waves in viscoelastic anisotropic media-I theory. Geophys J Int 161: 197-212

*Červený V, Pšenčík I (2006) Wave propagation in viscoelastic anisotropic media. In: 11IWSA, expand abst. Geophysics vol 71. p 18JF

*Chapman M (2006) Use of P-wave attenuation anisotropy as a fracture indicator. In: 12IWSA, expand abst. pp 33-34

Chapman M, Zatsepin SV, Crampin S (2002) Derivation of a microstructural poroelastic model. Geophys J Int 151:427-451

*Chapman M, Maultzsch S, Liu E, Li X-Y (2003) The effect of fluid saturation in an anisotropic multi-scale equant porosity model. J Appl Geophys 54:191-202, spec issue

*Chen T-C, Booth DC, Crampin S (1987) Shear-wave polarizations near the North Anatolian Fault-III observations of temporal changes. Geophys J R Astron Soc 91:287-311

*Chesnokov EM, Kukharenko YA, Kukharenko PY (1998) Frequency dependence of physical parameters of microinhomogeneous media. Rev Inst Fr Pet 53: 729-734

*Chichinina TI, Oblentseva IR (1998) Gyrotropy and anisotropy of rocks: similarities and differences. Rev Inst Fr Pet 53:655-667

*Christensen NI (1984) The magnitude, symmetry and origin of upper mantle anisotropy based on fabric analyses of ultramafic tectonites. Geophys J R Astron Soc 76:89-111

Crampin S (1966) Higher modes of seismic surface waves: propagation in Eurasia. Bull Seism Soc Am 56:12271239

Crampin S (1978) Seismic wave propagation through a cracked solid: polarization as a possible dilatancy diagnostic. Geophys J R Astron Soc 53:467-496

Crampin S (1981) A review of wave motion in anisotropic and cracked elastic-media. Wave Motion 3:343-391

*Crampin S (1984a) An introduction to wave propagation in anisotropic media. Geophys J R Astron Soc 76:17-28

*Crampin S (1984b) Effective anisotropic elastic-constants for wave propagation through cracked solids. Geophys J R Astron Soc 76:135-145

*Crampin S (1987) The basis for earthquake prediction. Geophys J R Astron Soc 91:331-347

*Crampin S (1991) Effects of point singularities on shearwave propagation in sedimentary basins. Geophys $\mathrm{J}$ Int 107:531-543

*Crampin S (1993a) Arguments for EDA. Can J Expl Geophys 29:18-30
*Crampin S (1993b) A review of the effects of crack geometry on wave propagation through aligned cracks. Can J Expl Geophys 29:3-17

Crampin S (1994) The fracture criticality of crustal rocks. Geophys J Int 118:428-438

*Crampin S (1998) Shear-wave splitting in a critical crust: the next step. Rev Inst Fr Pet 53:749-763

Crampin S (1999) Calculable fluid-rock interactions. J Geol Soc 156:501-514

Crampin S (2003a) The New Geophysics: shear-wave splitting provides a window into the crack-critical rock mass. Lead Edge 22:536-549

Crampin S (2003b) Aligned cracks not LPO as the cause of mantle anisotropy. In: EGS-AGU-EUG, Joint ass nice 2003, abst., P007

Crampin S (2004) The New Geophysics: implications for hydrocarbon recovery and possible contamination of time-lapse seismics. First Break 22:73-82

Crampin S (2006) The New Geophysics: a new understanding of fluid-rock deformation. In: Van Cotthem A, Charlier R, Thimus J-F, Tshibangu J-P (eds) Eurock 2006: multiphysics coupling and long term behaviour in rock mechanics. Taylor and Francis, London, pp 539-544

Crampin S, Taylor DB (1971) The propagation of surface waves in anisotropic media. Geophys J R Astron Soc 25:71-87

*Crampin S, King DW (1977) Evidence for anisotropy in the upper mantle beneath Eurasia from generalized higher mode surface waves. Geophys J R Astron Soc 49:59-85

Crampin S, Yedlin M (1981) Shear-wave singularities of wave propagation in anisotropic media. J Geophys 49:43-46

*Crampin S, Lovell JH (1991) A decade of shear-wave splitting in the Earth's crust: what does it mean? what use can we make of it? and what should we do next? Geophys J Int 107:387-407

Crampin S, Zatsepin SV (1997) Modelling the compliance of crustal rock II - response to temporal changes before earthquakes. Geophys J Int 129:495-506

*Crampin S, Chastin S (2001) Shear- wave splitting in a critical crust: II - compliant, calculable, controllable fluid-rock interactions. In: Ikelle L, Gangi A (eds) Anisotropy 2000. Soc expl geophys, open file publ vol 6. pp 21-48

Crampin S, Peacock S (2005) A review of shear-wave splitting in the compliant crack-critical anisotropic Earth. Wave Motion 41:59-77

Crampin S, Gao Y (2006a) A review of techniques for measuring shear-wave splitting above small earthquakes. Phys Earth Planet Inter 159:1-14

*Crampin S, Gao Y (2006b) The New Geophysics and the future of IWSA. In: 12IWSA, Expand abst. pp 109-110

Crampin S, Evans R, Üçer B, Doyle M, Davis JP, Yegorkina GV, Miller A (1980) Observations of dilatancy-induced polarization anomalies and earthquake prediction. Nature 286:874-877

Crampin S, Evans R, Doyle M, Davis JP (1981) Comments on papers about shear-wave splitting in dilatancy- 
induced anisotropy by I. N. Gupta and by A. Ryall and W. U. Savage. Bull Seismol Soc Am 71:375-377

*Crampin S, Chesnokov EM, Hipkin RG (1984a) Seismic anisotropy - the state of the art II. Geophys J R Astron Soc 76:1-16

*Crampin S, Evans R, Atkinson BK (1984b) Earthquake prediction: a new physical basis. Geophys J R Astron Soc 76:147-156

Crampin S, Evans R, Üçer SB (1985) Analysis of records of local earthquakes: the Turkish Dilatancy Projects (TDP1 and TDP2). Geophys J R Astron Soc 83:1-16

*Crampin S, Booth DC, Evans R, Peacock S, Fletcher JB (1990) Changes in shear-wave splitting at Anza near the time of the North Palm Springs Earthquake. J Geophys Res 95:11197-11212

Crampin S, Booth DC, Evans R, Peacock S, Fletcher JB (1991) Comment on "Quantitative Measurements of Shear Wave Polarizations at the Anza Seismic Network, Southern California Implications for Shear Wave Splitting and Earthquake Prediction" by R. C. Aster, P. M. Shearer and J. Berger. J Geophys Res 96:6403-6414

Crampin S, Volti T, Stefánsson R (1999) A successfully stress-forecast earthquake. Geophys J Int 138:F1-F5

Crampin S, Volti T, Chastin S, Gudmundsson A, Stefánsson R (2002) Indication of high pore-fluid pressures in a seismically-active fault zone. Geophys J Int 151:F1-F5

*Crampin S, Chastin S, Gao Y (2003) Shear-wave splitting in a critical crust: III-preliminary report of multivariable measurements in active tectonics. J Appl Geophys 54:265-277, spec issue

Crampin S, Peacock S, Gao Y, Chastin S (2004) The scatter of time-delays in shear-wave splitting above small earthquakes. Geophys J Int 156:39-44

*Crampin S, Gao Y, Zatsepin S, Browitt C, Keilis-Borok V, Suyehiro K, Walter L (2005) GEMS: the opportunity for a global earthquake stress-monitoring system for forecasting all damaging earthquakes worldwide. In: 11IWSA, expand abst. Geophysics vol 71. pp 24JF-25JF

Davis P (1989) The new physics: a synthesis. In: Davis P (ed) The new physics. Cambridge University Press, Cambridge, pp 1-6

*de Parscau J (1991) P- and SV-wave transversely isotropic phase velocities analysis from VSP data. Geophys J Int 107:629-638

*Evans R (1984) Effects of the free surface on shear wave trains. Geophys J R Astron Soc 76:165-172

*Evans R, Beamish D, Crampin S, Üçer SB (1987) The Turkish Dilatancy Project (TDP3): multidisciplinary studies of a potential earthquake source region. Geophys J R Astron Soc 91:265-286

*Fuchs K (1977) Seismic anisotropy of the subcrustal lithosphere as evidence for dynamical processes in the upper mantle. Geophys J R Astron Soc 49: 167-179

*Gajewski D, Pšenčík I (1987) Computation of highfrequency seismic wavefields in 3-D laterally inhomogeneous anisotropic media. Geophys J R Astron Soc 91:383-411
*Gajewski D, Pšenèík I (1990) Vertical seismic profile synthetics by dynamic ray tracing in laterally varying layered anisotropic structures. J Geophys Res 95: 11301-11315

*Galperina RM, Galperin EI (1987) Experimental study of shear-waves from shots in anisotropic media. Geophys J R Astron Soc 91:517-533

*Gao Y, Crampin S (2003) Temporal variations of shearwave splitting in field and laboratory studies in China. Spec issue. J Appl Geophys 54:279-287

Gao Y, Crampin S (2004) Observations of stress relaxation before earthquakes. Geophys J Int 157:578-582

Gao Y, Wang P, Zheng S, Wang M, Chen Y-T (1998) Temporal changes in shear-wave splitting at an isolated swarm of small earthquakes in 1992 near Dongfang, Hainan Island, Southern China. Geophys J Int 135:102-112

Gao Y, Hao P, Crampin S (2006) SWAS: a shear-wave analysis system for semi-automatic measurement of shear-wave splitting above small earthquakes. Phys Earth Planet Inter 159:71-89

Garbin HD, Knopoff L (1973) The compressional modulus of a material permeated by a random distribution of free circular cracks. Q Appl Math 31:453-464

Garbin HD, Knopoff L (1975a) The shear modulus of a material permeated by a random distribution of free circular cracks. Q Appl Math 33:296-300b

Garbin HD, Knopoff L (1975b) Elastic modulus of a medium with liquid-filled cracks. Q Appl Math 33: 301-303

* Garmany J (2001) Phase shifts and caustics in anisotropic media. In: Ikelle L, Gangi A (eds) Anisotropy 2000. Soc expl geophys, open file publ vol 6. pp 419-425

*Gledhill KR (1993) Shear waves recorded on close-spaced seismographs: II the complex anisotropic structure of the Wellington Peninsula, New Zealand. Can J Expl Geophys 29:299-314

* Graham G, Crampin S (1993) Shear-wave splitting from regional earthquakes in Turkey. Can J Expl Geophys 29:371-379

*Granger P-Y, Rollet A, Bonnet J-M (2001) Preliminary evaluation of azimuthal anisotropy over the Valhall Field using C-wave data. In: Ikelle L, Gangi A (eds) Anisotropy 2000. Soc expl geophys, open file publ vol 6. pp 49-67

*Gray D (2006) Observations of azimuthal anisotropy in prestacked seismic data. In: 12IWSA, expand abst pp 44-45

*Grechka V (2006) Penny-shaped fractures revisited. 11IWSA, expand abst. Geophysics 71:27JF

*Guest WS, Kendall J-M (1993) Modelling seismic waveforms in anisotropic inhomogeneous media using ray and Maslov asymptotic theory: applications to exploration seismology. Can J Expl Geophys 29: 78-92

*Gupta IN (1973a) Premonitory variations in S-wave velocity anisotropy before earthquakes in Nevada. Science 182:1129-1132

*Gupta IN (1973b) Dilatancy and premonitory variations of P, S travel times. Bull Seism Soc Am 63: 1157-1161 
*Gurevich B (2003) Elastic properties of saturated porous rock with aligned fractures. J Appl Geophys 54:203218, spec issue

Heffer KJ, Bevan TG (1990) Scaling relationships in natural fractures: data, theory, and application. Soc Pet Eng SPE 20981

*Helbig K (1996) Kelvin and the early history of seismic anisotropy. In: Fjær E, Holt RM, Rathore JS (eds) Seismic anisotropy. Soc Expl Geophys pp 15-36

*Helbig K (1998) A formalism for the consistent description of non-linear elasticity of anisotropic media. Rev Inst Fr Pet 53:693-708

*Helbig K, Rasolofosaon PNJ (2001) A theoretical paradigm for describing hysteresis and nonlinear elastricity in arbitrary anisotropic rocks. In: Ikelle L, Gangi A (eds) Anisotropy 2000, soc expl geophys, open file publ vol 6. pp 383-398

Hess H (1964) Seismic anisotropy of the uppermost mantle under oceans. Nature 203:629-631

*Holmes GM, Crampin S, Young RP (1993) Preliminary analysis of shear-wave splitting in granite at the Underground Research Laboratory, Manitoba. Can J Expl Geophys 29:140-152

Holmes GM, Crampin S, Young RP (2000) Seismic anisotropy in granite at the Underground Research Laboratory, Manitoba. Geophys Prosp 48:415-435

*Hornby BE (2001) Upscaling: elastic anisotropy from ultrasonic laboratory measurements of borehole seismic surveys. In: Hood JA (ed) Advances in anisotropy: selected theory, modeling, and case studies. Soc expl geophys, open file publ vol 5. pp 21-46

*Horne S, MacBeth C, Queen J (1996) Inversion for shear-wave splitting. In: Fjær E, Holt RM, Rathore JS (eds) Seismic anisotropy. Soc expl geophys. pp 489-517

Hudson JA (1980) Overall properties of a cracked solid. Math Proc Camb Phil Soc 88:371-384

Hudson JA (1981) Wave speeds and attenuation of elastic waves in material containing cracks. Geophys J R Astron Soc 64:133-150

Hudson JA (1986) A higher order approximation to the wave propagation constants for a cracked solid. Geophys J R Astron Soc 87:265-274

*Hudson JA (1991) Overall properties of heterogeneous material. Geophys J Int 107:505-511

*Igel H, Mora P, Riollet B (1993) Anisotropic wave propagation through finite-difference grids. Can J Expl Geophys 29:59-77

*Ikelle LT, Amundsen L (2001) AVO-A response of an anisotropic half-space for P-P, P-SV and P-SH data. In: Ikelle L, Gangi A (eds) Anisotropy 2000. Soc expl geophys, open file publ vol 6. pp 77-105

*Jenner E (2006) Time lapse behaviour of Pwave anisotropic attributes at Weyburn Field, Saskatchewan, Canada. 11IWSA, expand abst. Geophysics 71:27JF-28JF

* Kaneshima S (1990) Origin of crustal anisotropy: shearwave splitting studies in Japan. J Geophys Res 95:11121-11133

*Kebaili A, Le LH, Schmitt DR (1996) Slowness surface determination from slant stack curves. In: Fjær E, Holt
RM, Rathore JS (eds) Seismic anisotropy. Soc expl geophys, pp 518-555

*Keith CM, Crampin S (1977a) Seismic body waves in anisotropic refraction at a plane interface. Geophys J R Astron Soc 49:181-208

*Keith CM, Crampin S (1977b) Seismic body waves in anisotropic media: propagation through a layer. Geophys J R Astron Soc 49:209-223

*Keith CM, Crampin S (1977c) Seismic body waves in anisotropic media: synthetic seismograms. Geophys J R Astron Soc 49:225-243

*Kühnel T, Li X-Y (2001) Can we separate the effects of anisotropy and structure from surface seismic data. In: Hood JA (ed) Advances in anisotropy: selected theory, modeling, and case studies. Soc expl geophys, open file publ vol 5. pp 47-75

*Leary P (1991) Deep borehole log evidence for fractal distribution of fractures in crystalline rock. Geophys J Int 107:615-627

*Leary PC (2006) Crosswell seismic evidence for $\delta \approx$ $20-30 \%$ anisotropy in oil-field sand/shale formations, NE China and W Colorado. In: 12IWSA, expand abst, pp 55-56

*Leary PC, Li Y-G, Aki K (1987) Observation and modelling of fault-zone fracture seismic anisotropy-I P, $\mathrm{SV}$ and $\mathrm{SH}$ travel times. Geophys J R Astron Soc 91:461-484

*Leary PC, Crampin S, McEvilly TV (1990) Seismic fracture anisotropy in the Earth's crust: an overview. J Geophys Res 95:11105-11114

Leary P, Igel H, Mora P, Rodrigues D (1993) Finitedifference simulation of trapped wave propagation in fracture anisotropic low-velocity layers. Can J Expl Geophys 29:31-40

*Leslie JM, Lawton DC (2001) P-travel times below a dipping anisotropic thrust sheet. In: Hood JA (ed) Advances in anisotropy: selected theory, modeling, and case studies. Soc expl geophys, open file publ vol 5. pp 77-84

* Li X-Y (1998) Processing PP and PS waves in multicomponent sea-floor data for azimuthal anisotropy: theory and overview. Rev Inst Fr Pet 53:607-620

*Li Y-G, Leary PC (1990) Fault zone trapped waves. Bull Seism Soc Am 89:1245-1271

*Li X-Y, Crampin S (1991a) Complex component analysis of shear-wave splitting: theory. Geophys J Int 107: 597-604

*Li X-Y, Crampin S (1991b) Complex component analysis of shear-wave splitting: case studies. Geophys J Int 107:605-613

*Li X-Y, Yuan J (2003) Converted-wave moveout and conversion-point equations in layered VTI media: theory and applications. J Appl Geophys 54:297-318, spec issue

*Li Y-G, Leary PC, Aki K (1987) Observation and modelling of fault-zone fracture seismic anisotropy-II: Pwave polarization anomalies. Geophys J R Astron Soc 91:485-492

*Li Y-G, Leary PC, Aki K (1990) Ray series modeling of seismic wave travel times and amplitudes in three-dimensional heterogeneous anisotropic crys- 
talline rock: borehole vertical seismic profiling seismograms from the Mojave Desert. J Geophys Res 95:11225-11239

*Li X-Y, Mueller MC, Crampin S (1993) Case studies of shear-wave splitting in reflection surveys in South Texas. Can J Expl Geophys 29:189-215

*Liu E, Crampin S (1990) Effects of the internal shear wave window: comparison with anisotropy induced splitting. J Geophys Res 95:11275-11281

*Liu E, Crampin S, Queen JH (1991) Fracture detection using crosshole surveys and reverse vertical seismic profiles at the Conoco Borehole Test Facility, Oklahoma. Geophys J Int 107:449-463

*Liu E, Crampin S, Queen JH, Rizer WD (1993a) Velocity and attenuation anisotropy caused by microcracks and macrofractures in a multiazimuth reverse VSP. Can J Expl Geophys 29:117-188

*Liu Y, Booth DC, Crampin S, Evans R, Leary P (1993b) Shear-wave polarizations and possible temporal variations in shear-wave splitting at Parkfield. Can J Expl Geophys 29:380-390

*Liu E, Li X-Y, Queen JH (2001) Discrimination of pore fluids from $\mathrm{P}$ and converted shear-wave AVO analysis. In: Ikelle L, Gangi A (eds) Anisotropy 2000. Soc expl geophys, open file publ, vol 6. pp 203-221

*Liu E, Queen JH, Li X-Y, Chapman M, Maultzsch S, Lynn HB, Chesnokov EM (2003) Observation and analysis of frequency-dependent anisotropy from a multicomponent VSP at Bluebell-Altamont Field, Utah. J Appl Geophys 54:319-333, spec issue

*Liu E Chapman M, Queen JH, Lynn H (2006) Kinematic and dynamic anisotropy: implications of seismic fracture characterisations. In: 12IWSA, expand abst, pp 106-108

*Lou M, Crampin S (1991) Dispersion of guided waves in thin anisotropic waveguides. Geophys J Int 107:545555

*Lynn HB (1996) A geophysicist's view on seismic anisotropy. In: Fjær E, Holt RM, Rathore JS (eds) Seismic anisotropy, Soc expl geophys, pp 1-14

Lynn H (2004) The winds of change: anisotropic rocks ... their preferred direction of fluid flow and their associated seismic signatures. Soc expl geophys. (Distinguished Lecturer, Fall, 2004)

Lynn HB, Thomsen LA (1986) Reflection shear-wave data along the principal axes of azimuthal anisotropy. In: 56th ann int soc expl geophys mtg, 1986, Houston, expand abst, pp 473-476

*MacBeth C (1991a) Inverting shear-wave polarizations for anisotropy using three-component offset VSPs: synthetic seismograms. Geophys J Int 107:571-583

* MacBeth C (1991b) Inversion for subsurface anisotropy using estimates of shear-wave splitting. Geophys J Int 107:585-595

*Martynov VN, Mikhailenko BG (1984) Numerical modelling of propagation of elastic waves in anisotropic inhomogeneous media for the half-space and the sphere. Geophys J R Astron Soc 76:53-63

McEvilly TV (1964) Central US crust-upper mantle structure from Love and Rayleigh phase velocity inversion. Bull Seism Soc Am 54:1997-2016
*Mjelde R (1996) Seismic anisotropy and its geological implications on the Lofoten (Norway) continental shelf. In: Fjær E, Holt RM, Rathore JS (eds) Seismic anisotropy. Soc expl geophys, pp 684-732

*Mueller MC (1991) Prediction of lateral variability in fracture intensity using multicomponent shearwave surface seismic as a precursor to horizontal drilling in the Austin chalk. Geophys J Int 107:409415

*Niitsuma H, Tsuyuki K-I, Asanuma H (1993) Discrimination of split shear waves by wavelet transform. Can J Expl Geophys 29:106-113

Nur A, Simmons G (1969) Stress-induced anisotropy in rock: an experimental study. J Geophys Res 74:66676674

Nuttli O (1961) The effect of the earth's surface on the S wave particle motion. Bull Seism Soc Am 51:237246

Peacock S, Crampin S, Booth DC, Fletcher JB (1988) Shear-wave splitting in the Anza seismic gap, Southern California: temporal variations as possible precursors. J Geophys Res 93:3339-3356

*Petrashen GI, Kashtan BM (1984) Theory of bodywave propagation in inhomogeneous anisotropic media. Geophys J R Astron Soc 76:29-39

*Queen JH, Rizer WD (1990) An integrated study of seismic anisotropy and the natural fracture system at the Conoco Borehole Test Facility, Kay County, Oklahoma. J Geophys Res 95:11255-11273

Raitt RW, Shor GG, Francis TJG, Morris GB (1969) Anisotropy of the Pacific upper mantle. J Geophys Res 74:3095-3109

*Rasolofosaon PNJ (2006) The unreasonable success of Gassmann's Theory-revisited. In: 12IWSA, expand abst, pp 86-87

*Rasolofosaon PNJ, Yin H (1996) Simultaneous characterization of anisotropy and nonlinearity in arbitrary elastic media-reflections on experimental data. In: Fjær E, Holt RM, Rathore JS (eds) Seismic anisotropy. Soc expl geophys, pp 141-179

Rathore JS, Fjær E, Holt RM, Renlie L (1995) P- and Swave anisotropy of a synthetic sandstone with controlled crack geometry. Geophys Prosp 43:711-728

Raymer DG, Kendall JM (1998) Seismic anisotropy in salt structures due to preferred crystal orientation. Rev Inst Fr Pet 53:585-594

*Rommel BE, Tsvankin I (2001) Analytic description of $\mathrm{P}$-wave ray direction and polarization in orthorhombic media. In: Ikelle L, Gangi A (eds) Anisotropy 2000. Soc expl geophys, open file publ vol 6 . pp 363-381

*Savage M (2006) An overview of seismic anisotropy determined from earthquakes: from the inner cores to the crust. In: 12IWSA, expand abst, pp i-ii

*Savage MK, Peppin WA, Vetter UR (1990) Shear-wave anisotropy and stress direction in and near Long Valley Caldera, California, 1979-1988. Geophys J R Astron Soc 95:11165-11177

*Schlue JW, Knopoff L (1977) Shear-wave polarization anisotropy in the Pacific Basin. Geophys J R Astron Soc 49:145-165 
*Shepherd TJ (1990) Geological link between fluid inclusions, dilatent microcracks, and paleostress field. J Geophys Res 95:11115-11120

*Shih XR, Meyer RP (1990) Observation of shear wave splitting from natural events South Moat of Long Valley Caldera, California, June 29 to August 12, 1982. J Geophys Res 95:11179-11195

Shih XR, Meyer RP, Schneider JF (1989) An automated analytic method to determine shear-wave anisotropy. Tectonophysics 165:271-278

*Skjærstein A, Fjær E (2001) Angular dependent attenuation in a sandstone with parallel cracks. In: Hood JA (ed) Advances in anisotropy: selected theory, modeling, and case studies. Soc expl geophys, open file publ vol 5. pp 205-215

*Slater C, Crampin S, Brodov LY, Kuznetsov VM (1993) Observations of anisotropic cusps in transversely isotropic clay. Can J Expl Geophys 29:216-226

*Stawicki AW, Lynn HB (1996) Effects of complex tectonic strain observed in two multi-component multiazimuth VSPs from Pakistan. In: Fjær E, Holt RM, Rathore JS (eds) Seismic anisotropy. Soc expl geophys, pp 645-683

*Taylor DB (1987) Double contour integration for transmission from point sources through anisotropic layers. Geophys J R Astron Soc 91:373-381

Taylor DB (1990) ANISEIS manual, applied geophysical software.macrocltd@blueyonder.co.uk

Thomsen L (1986) Weak elastic anisotropy. Geophysics 51:1954-1966

Thomsen L (2002) Understanding seismic anisotropy in exploration and exploitation. Soc Expl Geophys (Distinguished Short Course)

*Thomsen L, Dellinger J (2003) On shear-wave triplication in transversely isotropic media. J Appl Geophys 54:289-296, spec issue

Tsvankin ID (1996) Anisotropic parameters and P-wave velocity for orthorhombic media. Geophysics 62:12921309

*Tsvankin ID, Chesnokov EM (1990) Synthesis of body wave seismograms from point sources in anisotropic media. J Geophys Res 95:11317-11331

*Turcotte DL (1992) Fractals and chaos in geology and geophysics. Cambridge University Press, Cambridge, p 221
*Vikhorev AA, Ammerman M, Bayuk I, Abaseyev S, Chesnokov E (2006) Scale dependent anisotropy based upon multiscale data. 11IWSA, expand abst. Geophysics 71:15JF

Volti T, Crampin S (2003a) A four-year study of shearwave splitting in Iceland: 1 background and preliminary analysis. In: Nieuwland DA (ed) New insights into structural interpretation and modelling. Geol soc lond, spec publ, vol 212. pp 117-133

Volti T, Crampin S (2003b) A four-year study of shearwave splitting in Iceland: 2 temporal changes before earthquakes and volcanic eruptions. In: Nieuwland DA (ed) New insights into structural interpretation and modelling. Geol soc lond, spec publ vol 212. pp 135-149

*Wild P, Crampin S (1991) The range of effects of azimuthal isotropy and EDA-anisotropy in sedimentary basins. Geophys J Int 107:513-529

*Wild P, MacBeth C, Crampin S, Li X-Y, Yardley G (1993) Processing and interpreting vector wave-field data. Can J Expl Geophys 29:117-124

*Williamson P, Maocec E (2001) Estimation of local anisotropy using polarisations and travel times from the Oseberg 3D VSP. In: Ikelle L, Gangi A (eds) Anisotropy 2000. Soc expl geophys, open file publ. vol 6. pp 339-348

*Yao C, Xiong Y (1993a) Far-field radiation pattern from an anisotropic dislocation point source. Can J Expl Geophys 29:315-323

*Yao C, Xiong Y (1993b) Shear-wave splitting from local earthquakes modelled by synthetic seismograms. Can J Expl Geophys 29:324-331

Zatsepin SV, Crampin S (1997) Modelling the compliance of crustal rock: I-response of shear-wave splitting to differential stress. Geophys J Int 129:477494

*Zhang Z, He Q, Teng J, Wang A, Wei J (1993) Simulation of 3-component seismic records in a 2dimensional transversely isotropic medium with finite difference method. Can J Expl Geophys 29: $51-58$

*Zheng X, Han K, Liu E (2006) Investigations on the limitation of Hudson's theory by boundary element modelling. In: 12IWSA, expand abst, pp 5960 